\title{
Place Matters: \\ Poverty and Development Challenges in Amenity Rich, Declining Resource Dependent and Chronically Poor Regions
}

\author{
Havens Center \\ University of Wisconsin \\ March 12, 2008 \\ The Carsey Institute \\ University of New Hampshire
}




\section{What I will do today}

- Talk about the Carsey Institute and our efforts to be a new kind of applied and policy research institute.

- Describe the changes sweeping across rural America and how they play out in the "three rural Americas."

- Suggest the diverse development challenges in each type of place. 


\section{Building Knowledge for Families and Communities}

- Applied and policy research

- Rigorous methodological approach

- Genuine connections with policy makers and practitioners running programs - listen and be an accessible resource with good outreach

- Build the fields we are engaged in

- Youth, Working Family Policy, Sustainable Development and Rural Area Studies

- Support faculty and train students 


\section{Rural America Today}

- 50 million people live in small town and rural communities, $17 \%$ of the US population, on $80 \%$ of the land

- Slow growth over the last century, compared to urban America

- Trends vary by region and type of rural community

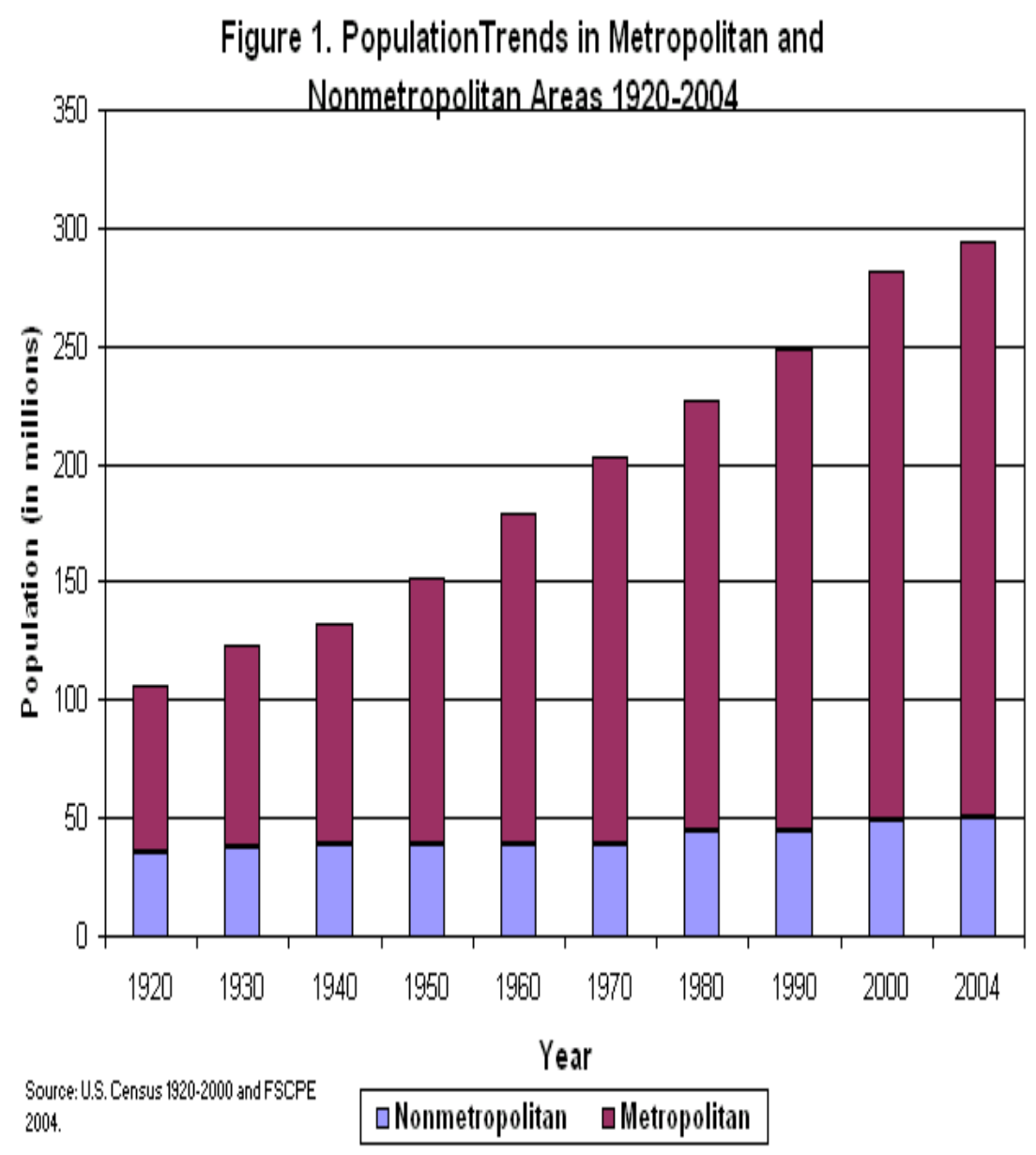




\section{Important challenges across America}

ECONOMIC: Growing inequality, stagnant wages since the 1970s; loss of blue collar jobs \& the blue collar middle class; decades of neglect in poor areas

DEMOGRAPHIC: Aging population, youth outmigration in rural areas, \& growing immigrant population

ENVIRONMENTAL: environmental degradation \& stress on natural resources; climate change and energy issues 
Rural America has depended heavily on low skill manufacturing - the jobs threatened by globalization ( $42 \%$ of rural jobs are low skill)

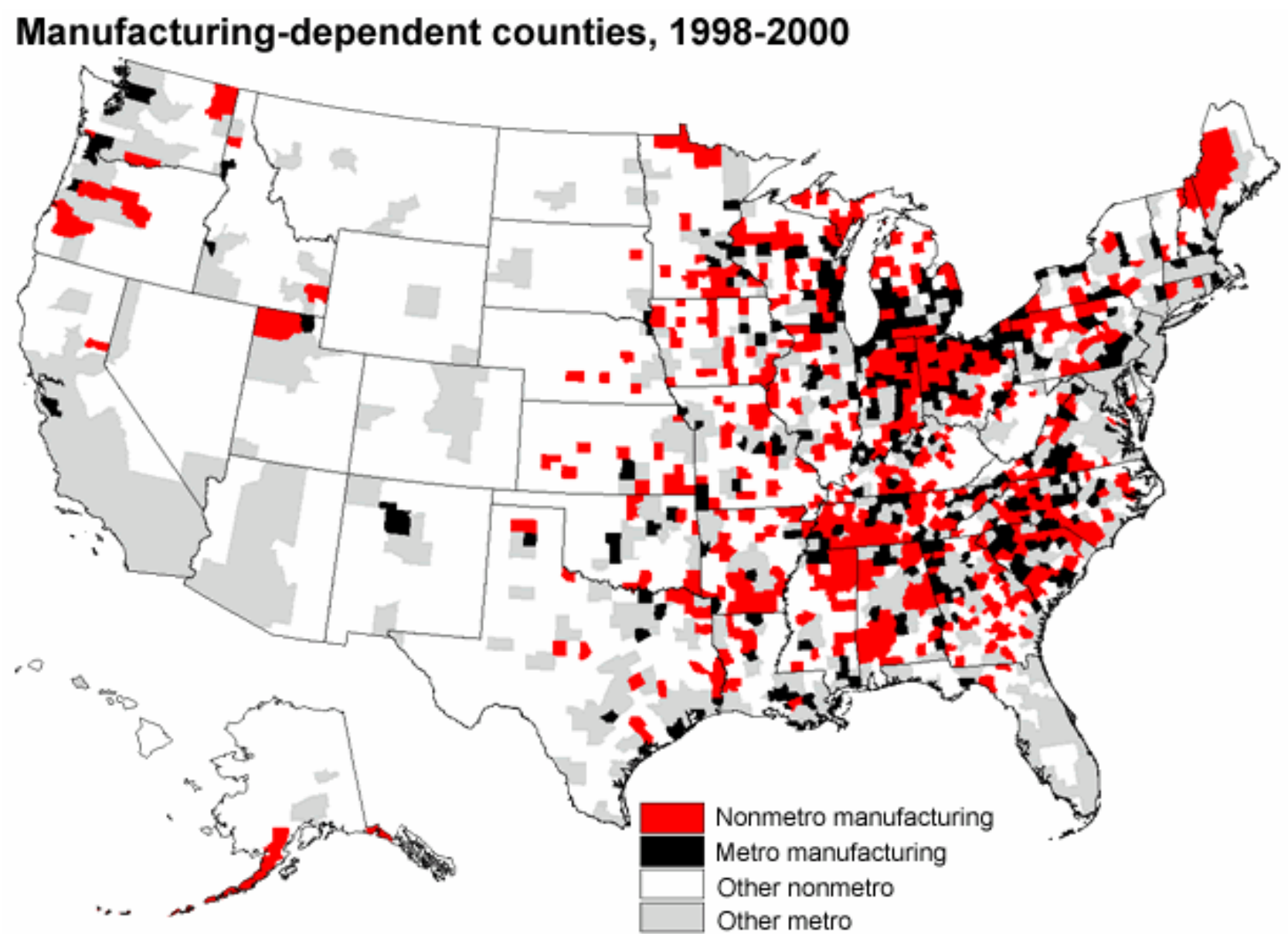

Manufacturing-dependent counties--an annual average of 25 percent or more of total county earnings derived from manufacturing during 1998-2000.

Source: Economic Research Service, USDA. 


\section{Demographic shifts: Young leave, older people come, especially to places with natural amenities}

Though youth outmigration is declining overall...and other age groups are coming into rural

communities

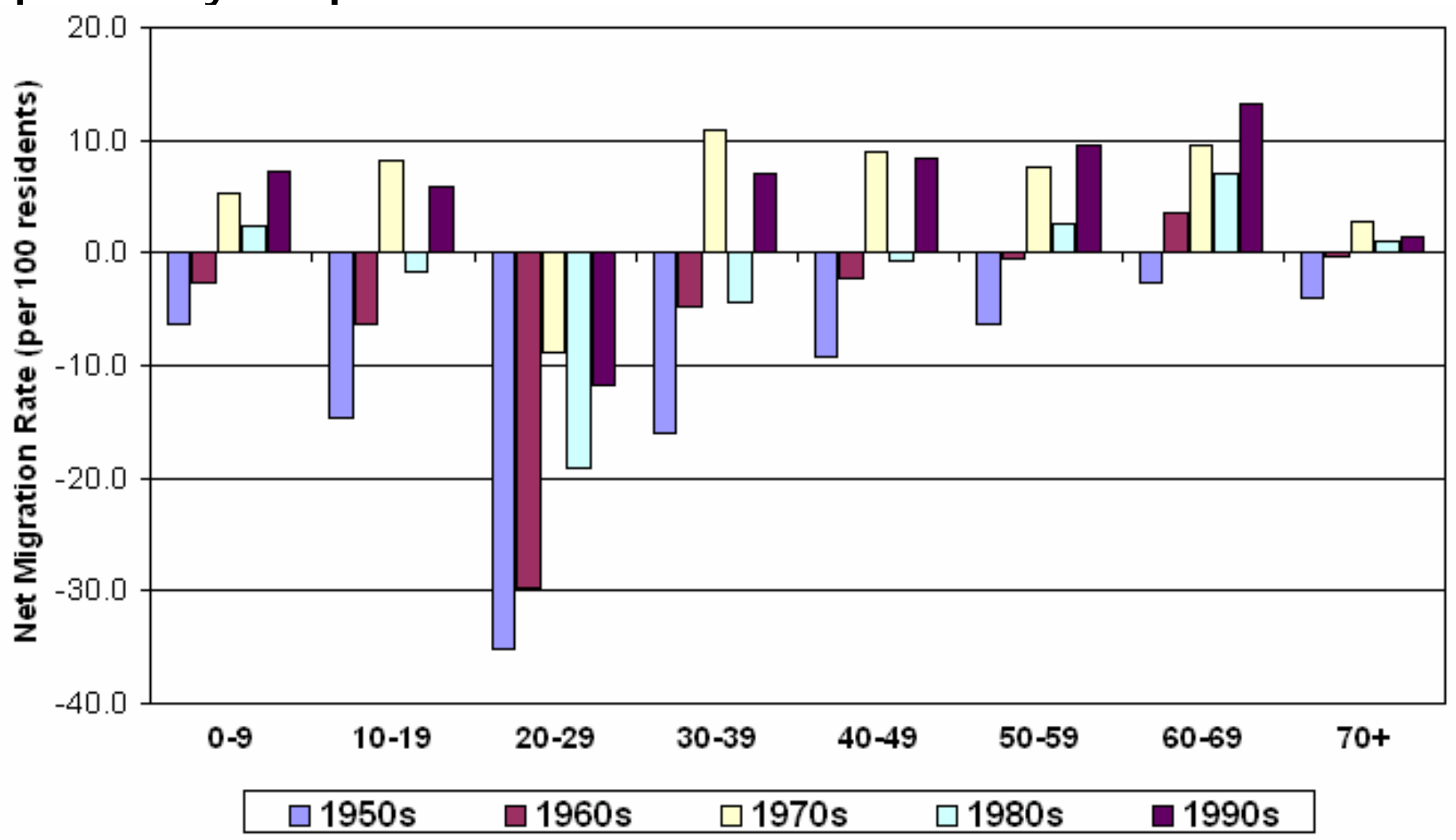

Source: Johnson et. al., 2005. 
Hispanic Population Growth Patterns 1990 to 2005

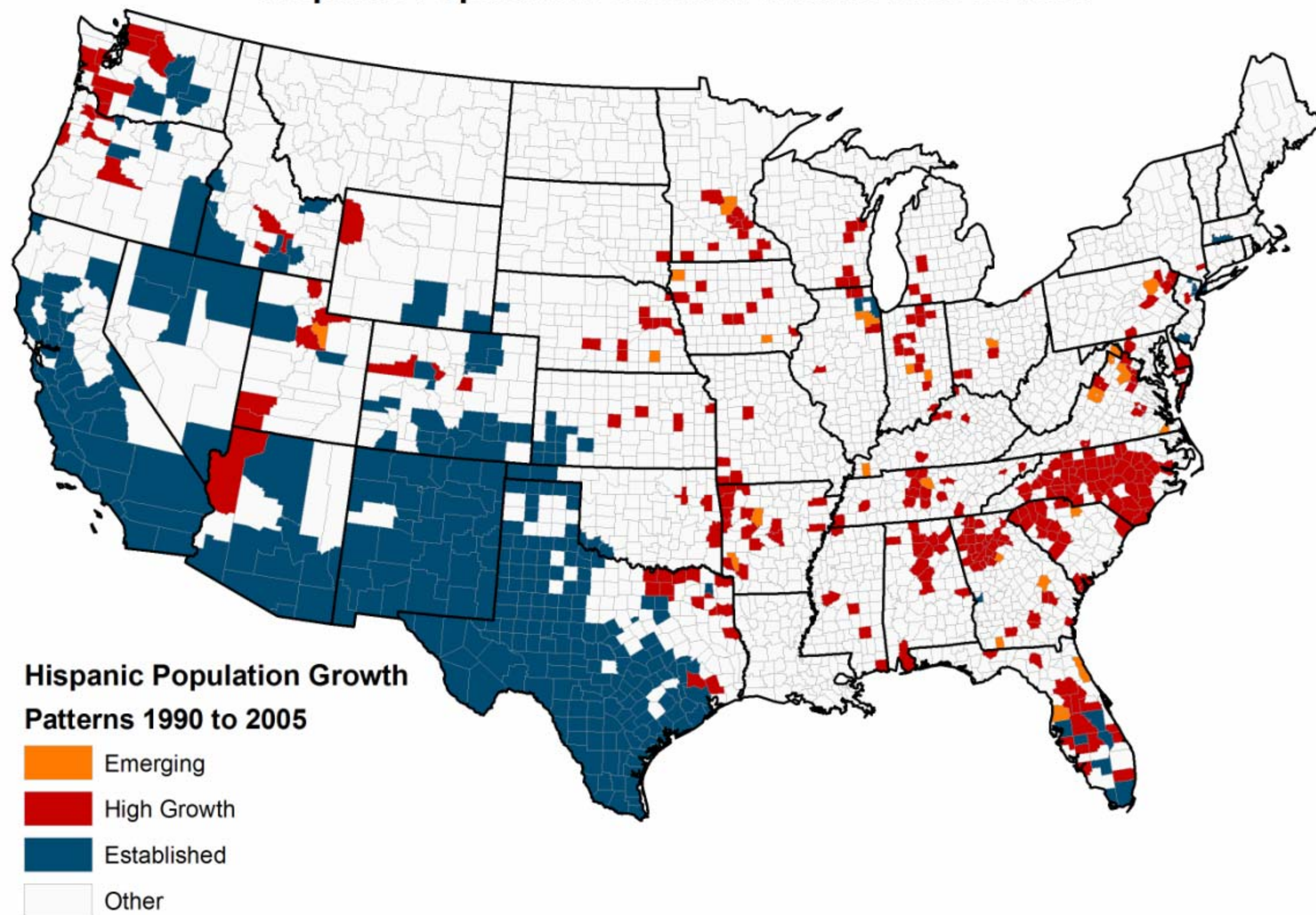

Source: 1990 and 2000 Census and 2005 Census Estimates Analysis: K.M. Johnson and D.T Lichter, 2007 


\section{Today there are three rural Americas, each with its own challenges}

- Amenity rich areas that are growing as baby boomers retire, as more people buy $2^{\text {nd }}$ homes, and as "footloose professionals" choose to settle in small town communities with rich natural amenities or outside large cities

- Declining and transitioning resource dependent areas, where once agriculture, timber, mining or related manufacturing industries supported a solid blue collar middle class, albeit sometimes with booms and busts

- Chronically poor communities, places with majority people of color, as well as Appalachia and the Ozarks, where decades of resource extraction and underinvestment in communities have left a legacy of poverty, low education and broken civic institutions 


\section{Amenity-rich areas are growing and likely to grow more over the next decade}

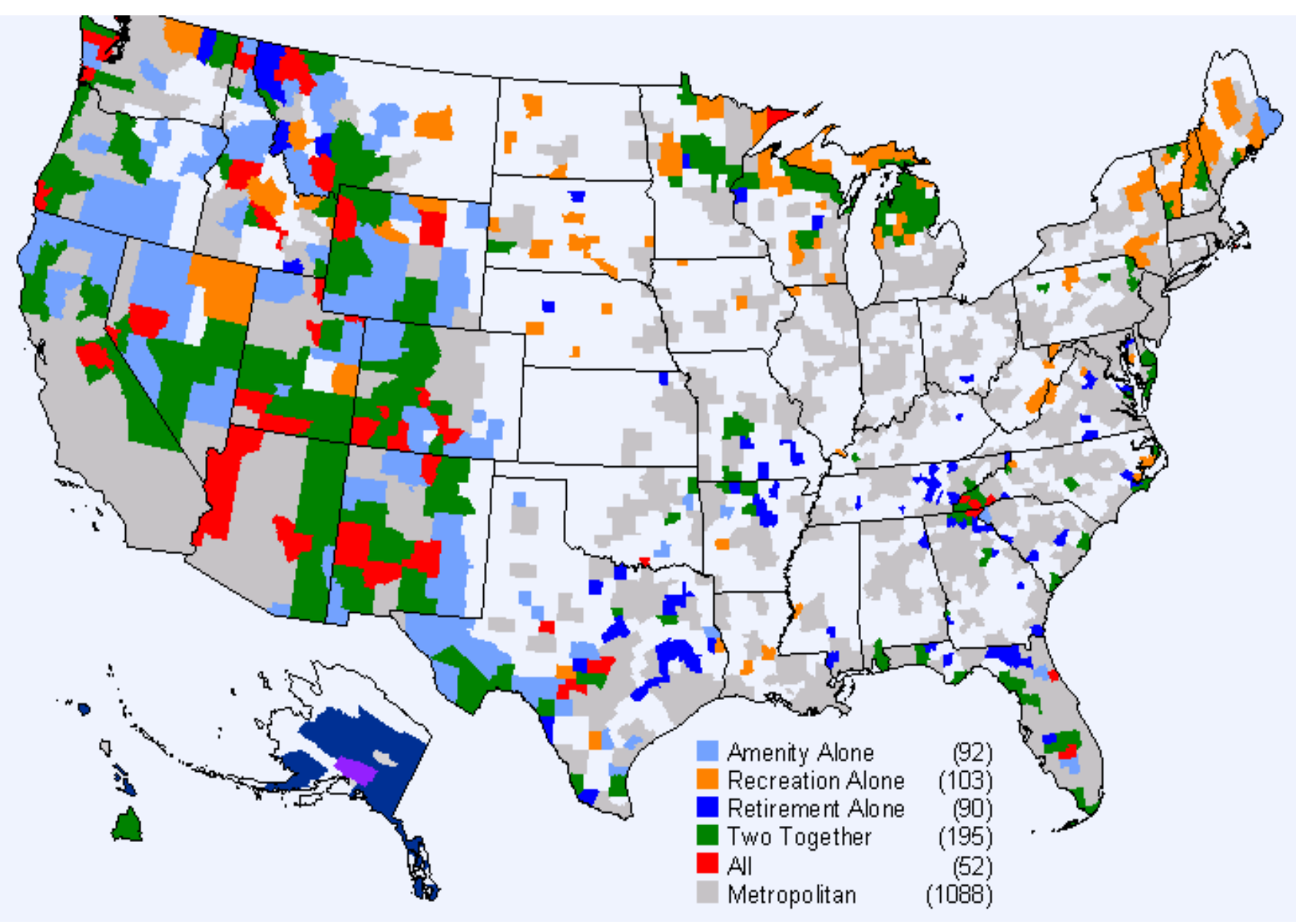




\section{Persistent population loss plagues other resource dependent areas}

- Loss is concentrated in the Great Plains, parts of the Corn Belt, the lower Mississippi Valley, and Appalachia

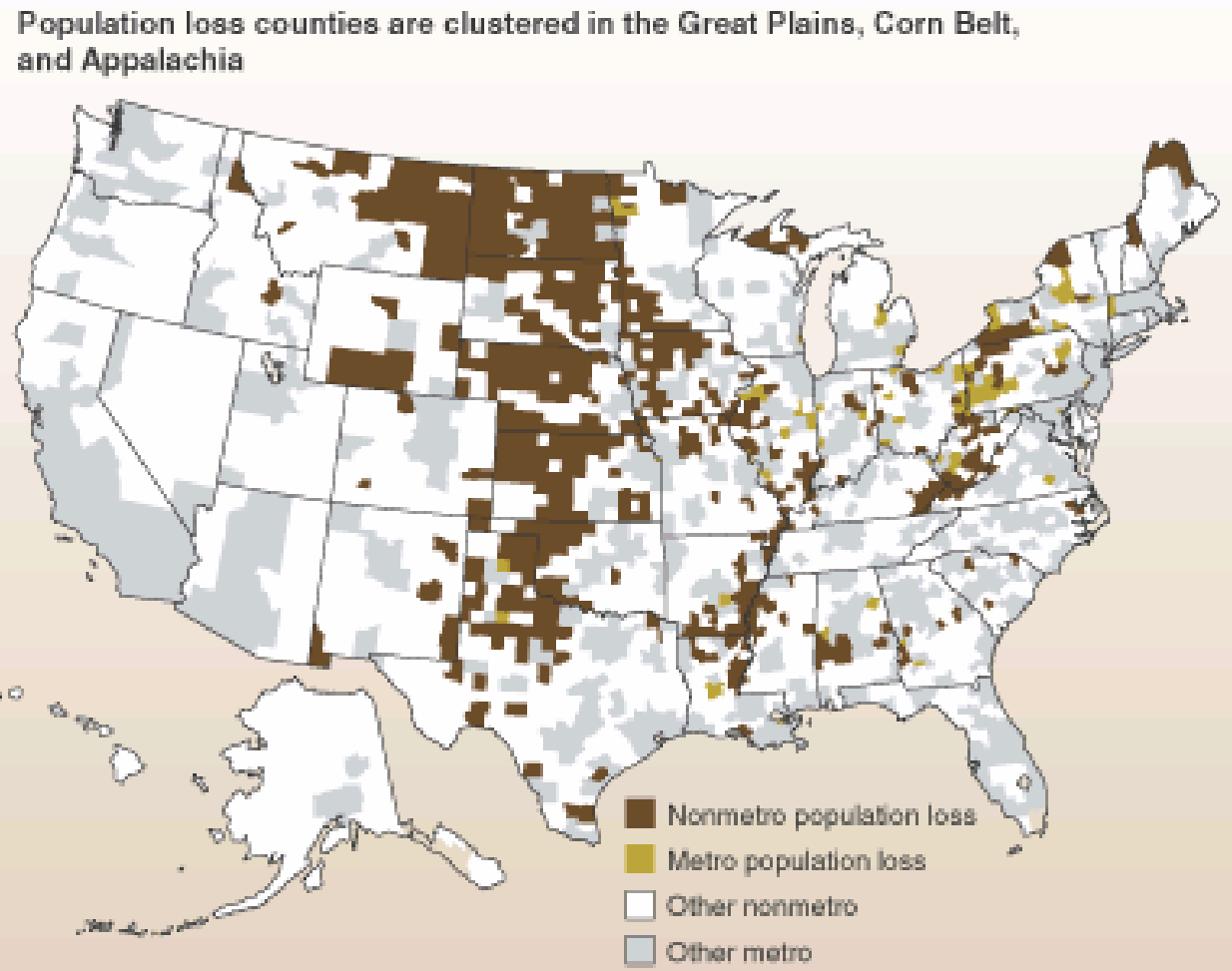

Population loss coumfies-number of residents declined both between 1960 and 1990 and beteeen 1960 and 2000. Prepared ty ERS using U.S. Census Quraau data. 
Current rural policy largely relies on the Farm Bill: these declining areas are the same ones where farm subsidies are the highest: USDA Subsidies by Congressional District, 1995-2004

Five percent of the nation's 435 congressional districts collected more than half of all subsidies over the past decadesome $\$ 69$ billion

(Environmental Working Group ewg.org).

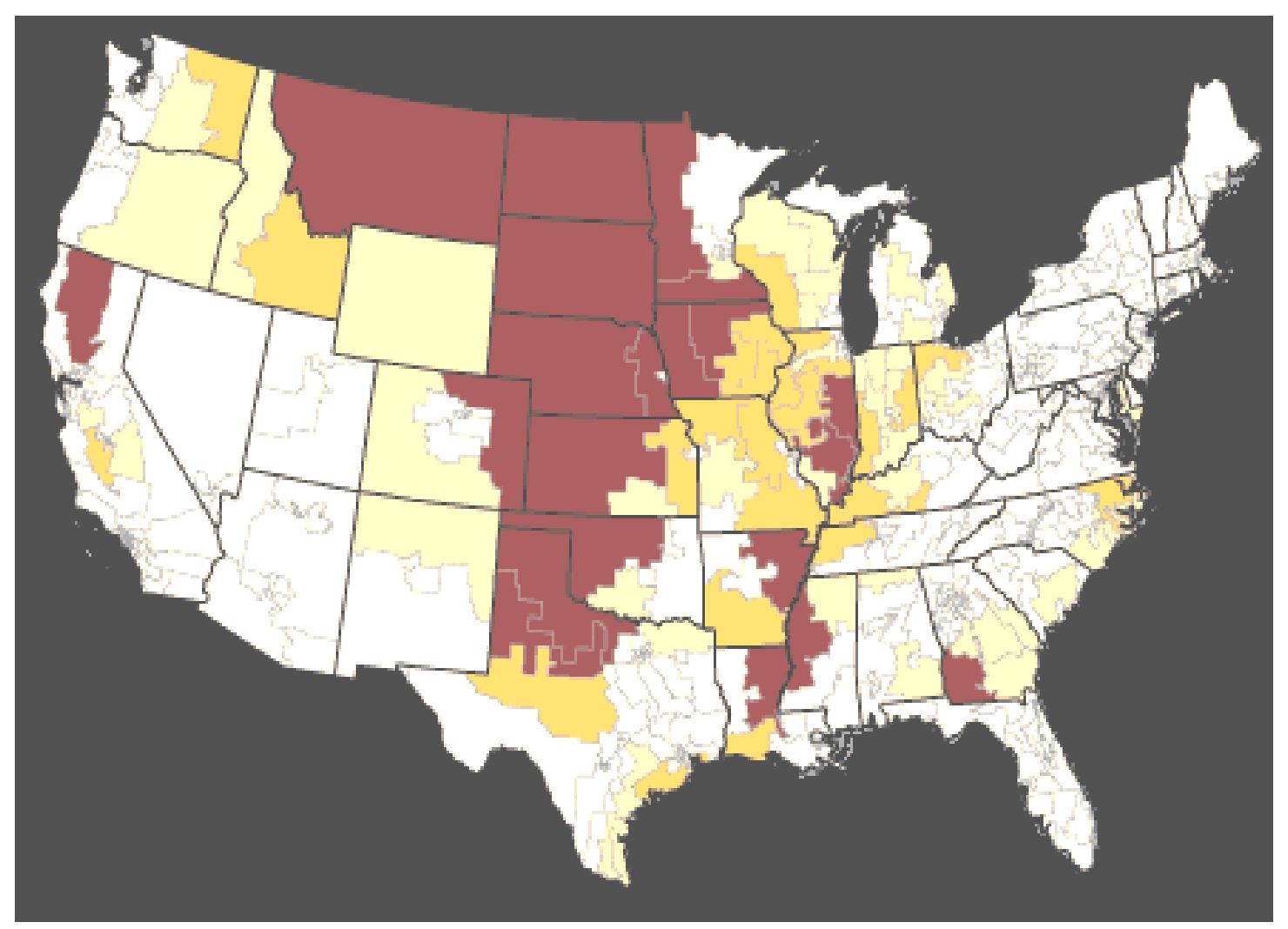




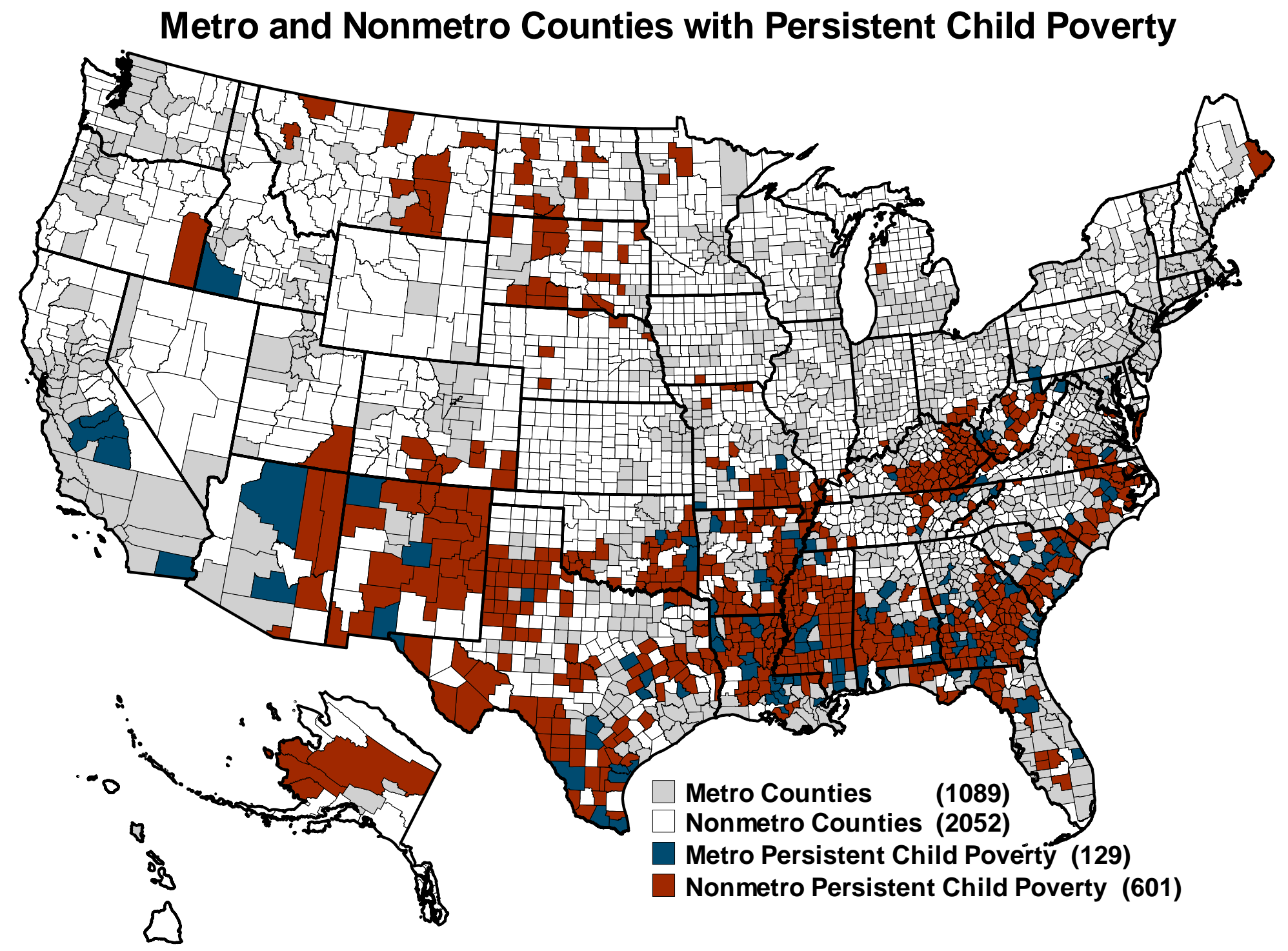

Data: Census data supplied by Economic Research Service, U.S.D.A. 


\section{And these are the places where $1 / 4$ or more of working age adults have dropped out of high school}

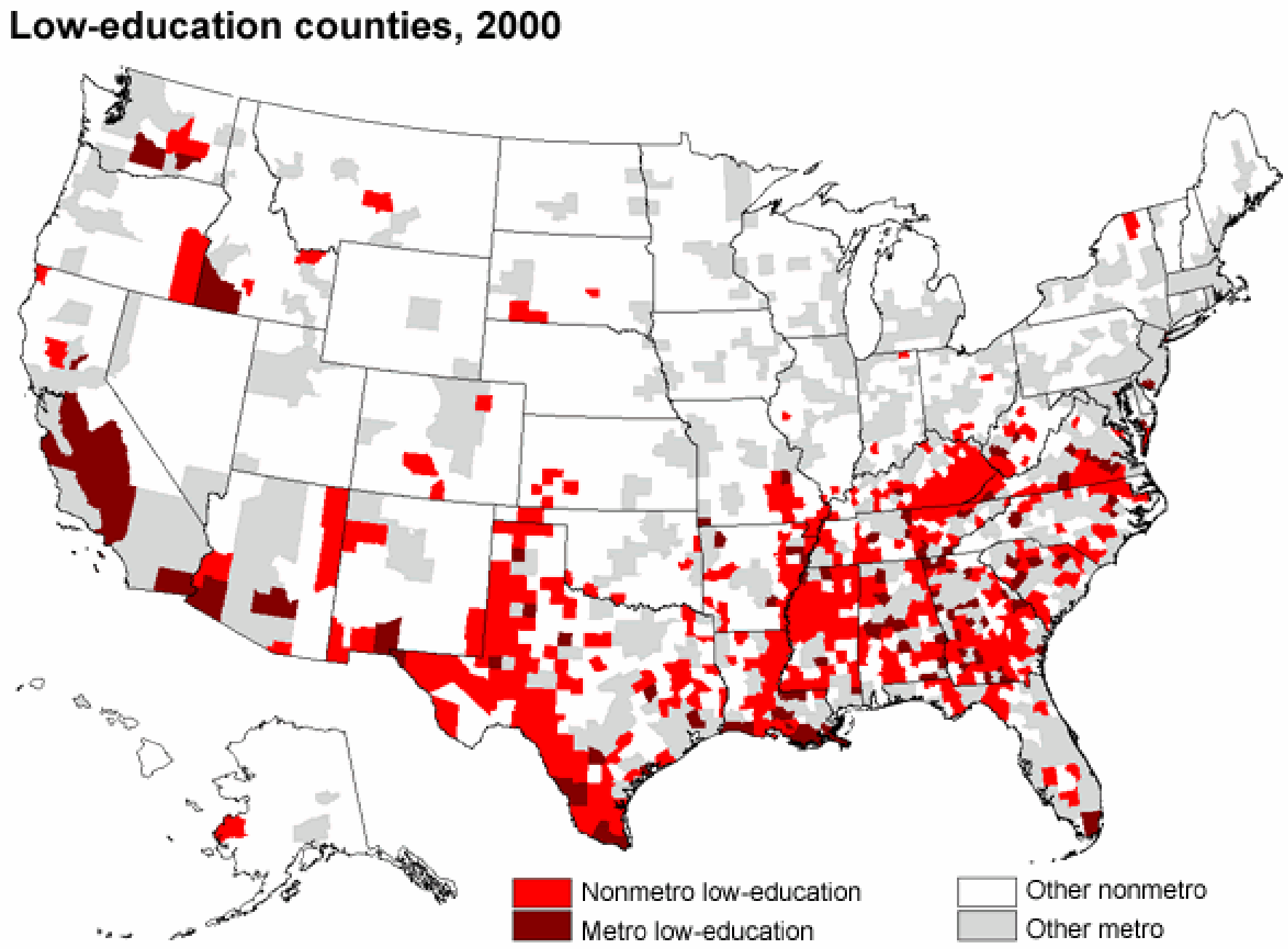

Low-education counties--25 percent or more of residents 25-64 years old had neither a high school diploma nor GED in 2000.

Source: Economic Research Service, USDA. 
A Fresh Look at Migration, Coping with new Economic Conditions, and Perspectives on Community and the Environment

Rocky Mountain West - Amenity Boom

Pacific Northwest - Amenity \& Decline

Northeast Forest - Amenity \& Decline

Midwestern Plains - Decline

Central Appalachia - Chronic Poverty

Mississippi Delta - Chronic Poverty

Alabama's Black Belt - Chronic Poverty 


\section{New Areas Coming}

- Michigan's Upper Peninsula

- Nebraska's Panhandle

- Indian Country - WI and AZ

- Maybe Western North Carolina 
Closer Look at The Three Rural Americas: Carsey Institute Survey of 6,500 rural adults

\begin{tabular}{|l|l|l|l|l|}
\hline & $\begin{array}{l}\text { Popn } \\
\text { change } \\
1990-05\end{array}$ & $\begin{array}{l}25-34 \text { year } \\
\text { olds change } \\
1990-05\end{array}$ & $\begin{array}{l}\text { Pct 16-64 } \\
\text { Working } \\
2000\end{array}$ & $\begin{array}{l}\text { Pct Poor } \\
2004\end{array}$ \\
\hline $\begin{array}{l}\text { Amenity Boom } \\
\text { Rocky Mtn }\end{array}$ & $+71 \%$ & $+41 \%$ & $72 \%$ & $10 \%$ \\
\hline $\begin{array}{l}\text { Amenity and } \\
\text { Decline } \\
\text { Pacific NW }\end{array}$ & $+12 \%$ & $-1 \%$ & $68 \%$ & $14 \%$ \\
\hline $\begin{array}{l}\text { Amenity and } \\
\text { Decline } \\
\text { Northeast }\end{array}$ & $+3 \%$ & $-24 \%$ & $73 \%$ & $12 \%$ \\
\hline $\begin{array}{l}\text { Decline } \\
\text { Midwest }\end{array}$ & $-19 \%$ & $-50 \%$ & $78 \%$ & $11 \%$ \\
\hline $\begin{array}{l}\text { Chronic poverty } \\
\text { Appalachia }\end{array}$ & $-12 \%$ & $-28 \%$ & $43 \%$ & $27 \%$ \\
\hline $\begin{array}{l}\text { Chronic poverty } \\
\text { Delta }\end{array}$ & $-3 \%$ & $+2 \%$ & $56 \%$ & $29 \%$ \\
\hline
\end{tabular}


Net Migration for Amenity Growth in Northwest Communities, 1980 to 2000

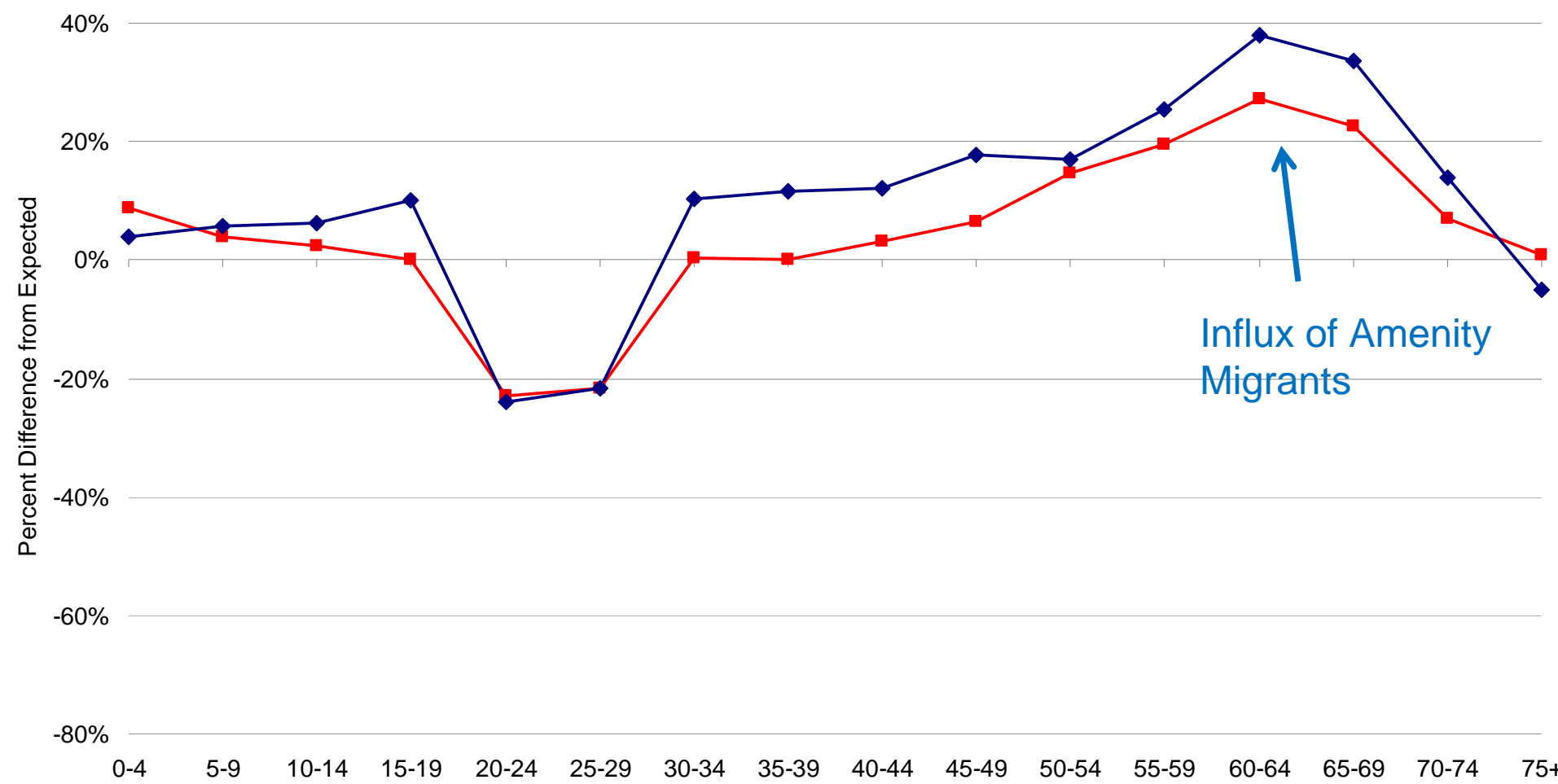




\section{Net Migration for Declining Midwestern Communities,}

1980 to 2000

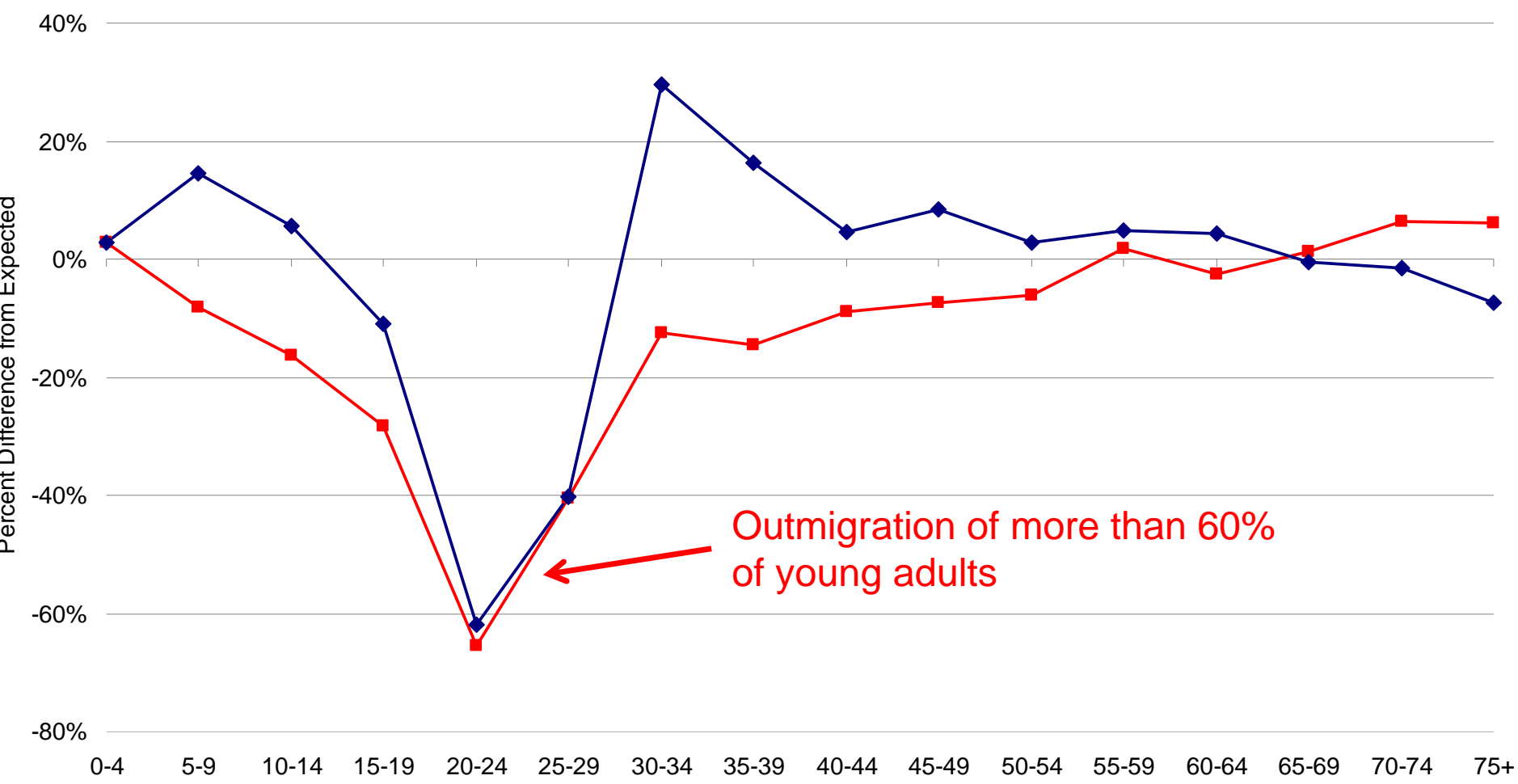

Analysis: K.M. Johnson, Carsey Institute

Data: Johnson, et al. 2005. Demography 42: 791-812.

Counties: Osborne (KS), Republic (KS), Smith (KS), and Jew ell (KS) 
Net Migration for Chronically Depressed Communities in Appalachia, 1980 to 2000

$40 \%$

$20 \%$

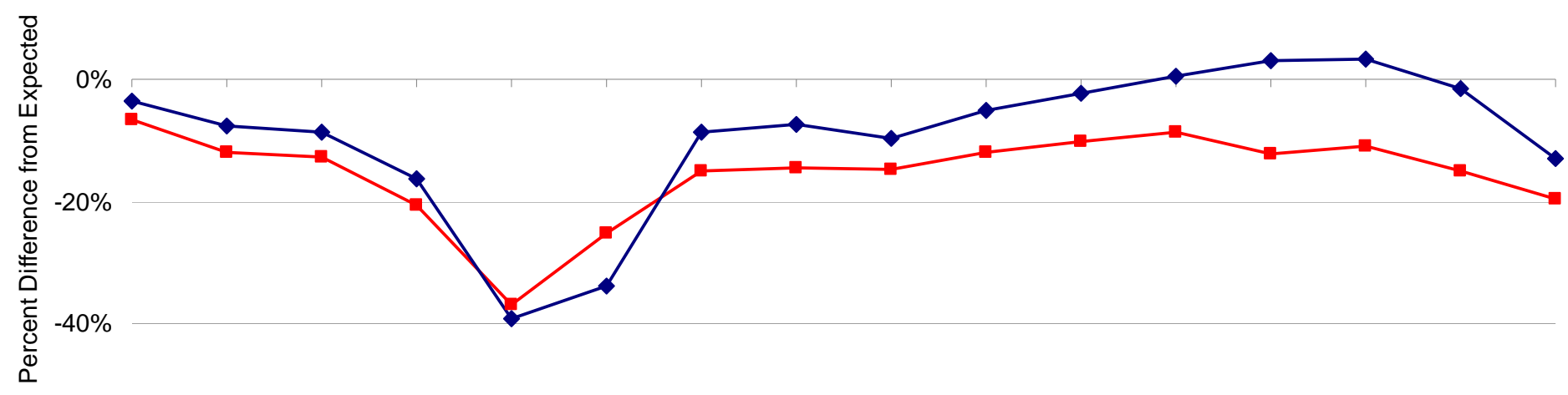

$-60 \%$

$-80 \%$
$0-4$
$5-9$
10-14
15-19 20-24
$25-29 \quad 30-34$
35-39
40-44
$45-49$
$50-54 \quad 55-59$
$60-64 \quad 65-69$
$70-74 \quad 75+$ 
Net Migration for Chronically Depressed Communities in Alabama's

Black Belt, 1980 to 2000

$40 \%$

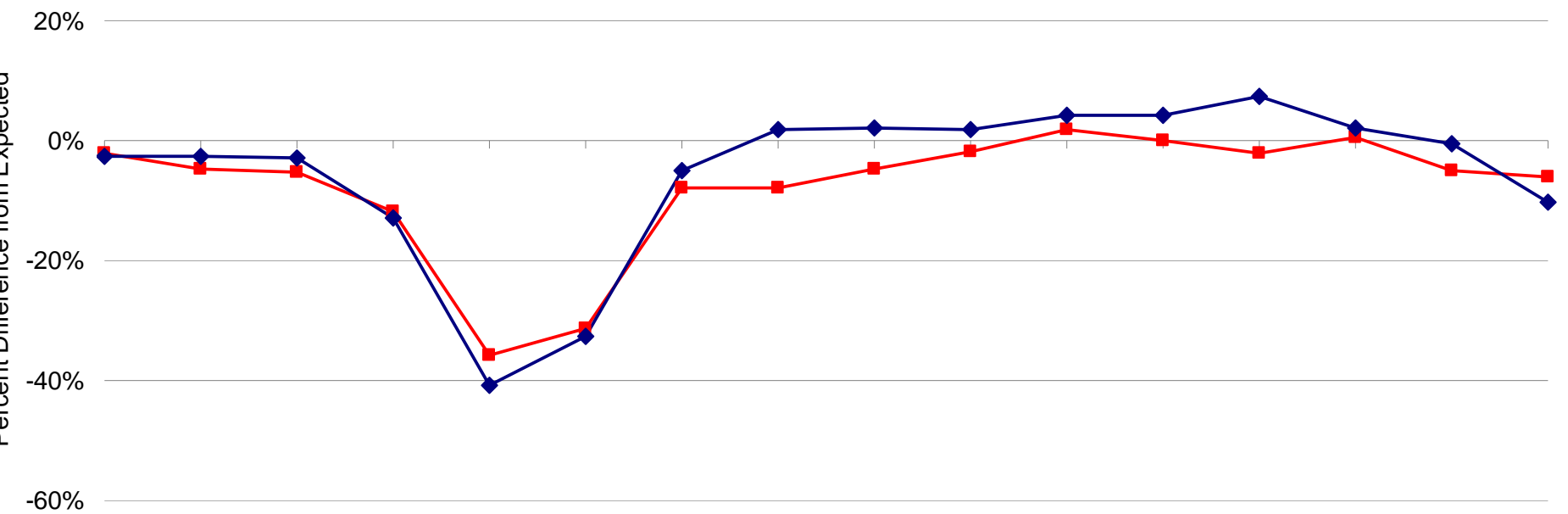

$-80 \%$

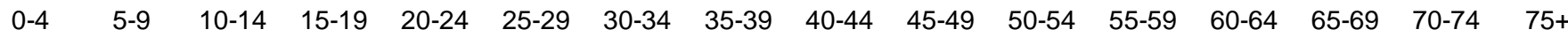

Analysis: K.M. Johnson, Carsey Institute

Data: Johnson, et al. 2005. Demography 42: 791-812.

Counties: Choctaw (AL), Clarke (AL), Marengo (AL), and Wilcox (AL)

$\neg-1980-1990 \multimap 1990-2000$ 


\section{Age Pyramid \\ Northwest Amenity Growth Communities (2006)}

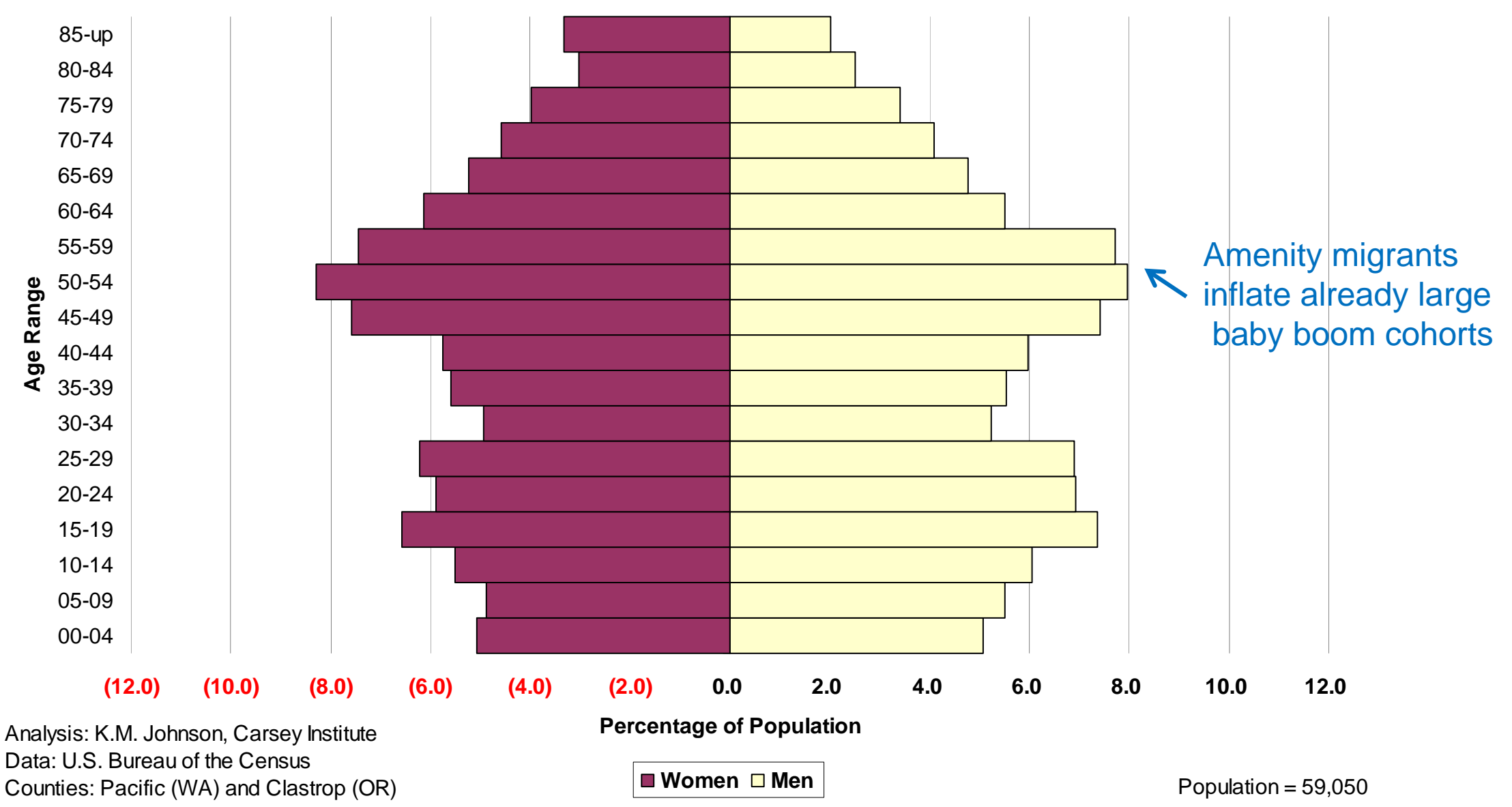




\section{Age Pyramid Declining Midwestern Communities (2006)}

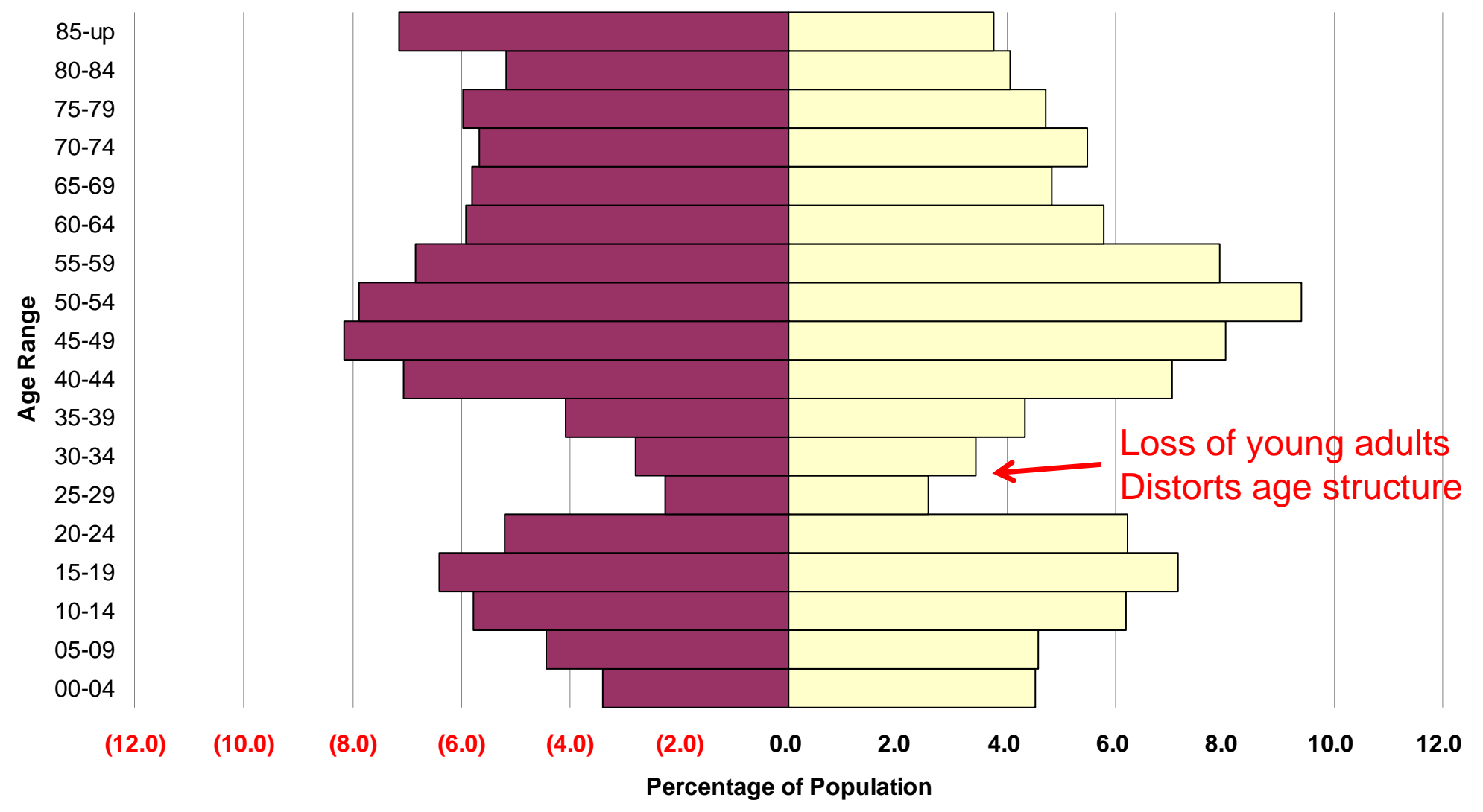




\section{Let's look at what's going on in our three (or four) types of areas}

- Amenity rich areas

- Declining resource dependent areas

- Transitioning amenity/decline areas

- Chronically poor areas

- Clusters of counties where we conducted 1-1500 interviews with a random sample of adults in the area (with $\sim 40,000$ popn.) 


\section{Still a small middle income group in poor areas}

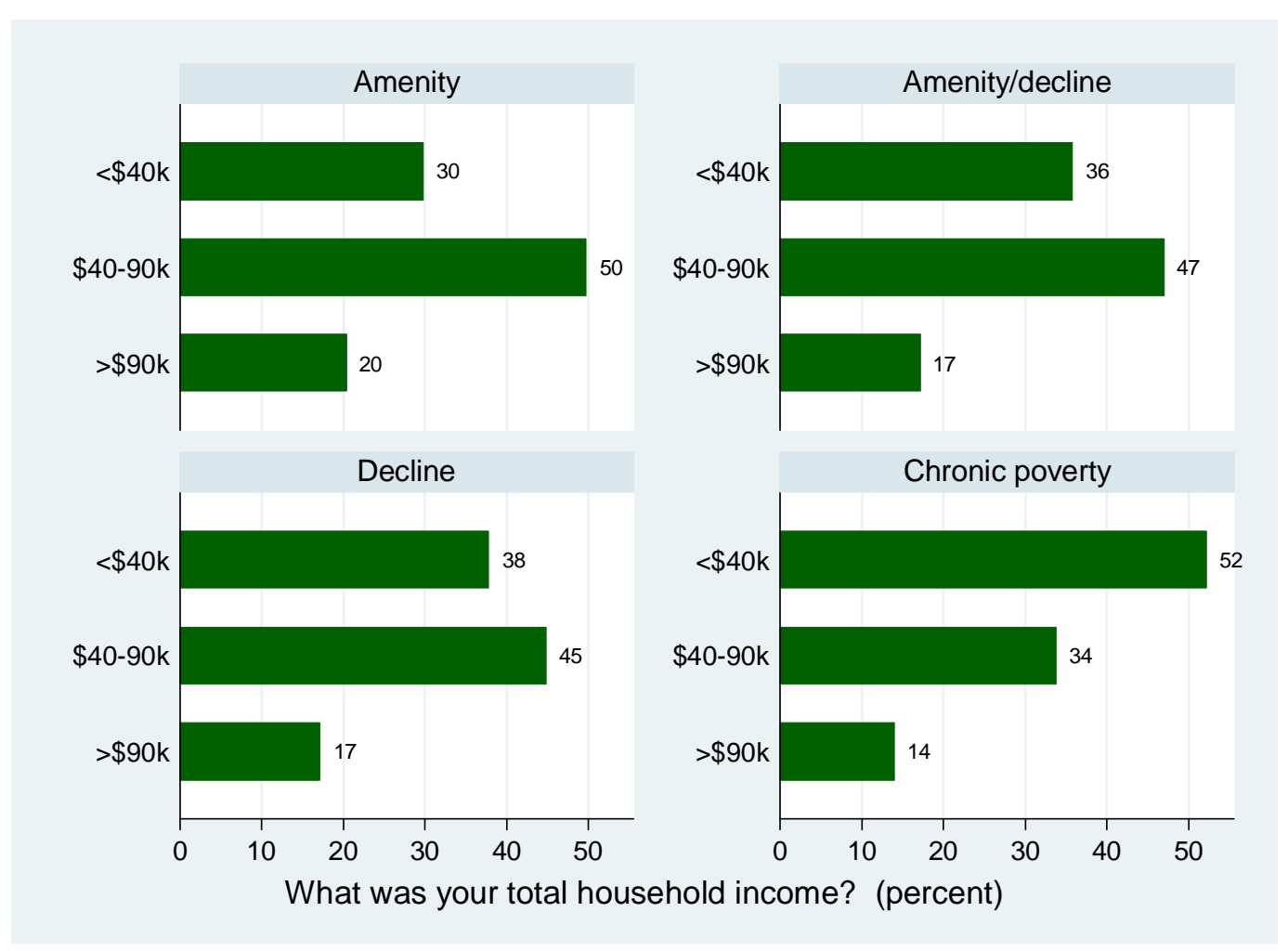




\section{Amenity rich areas are college grad rich}

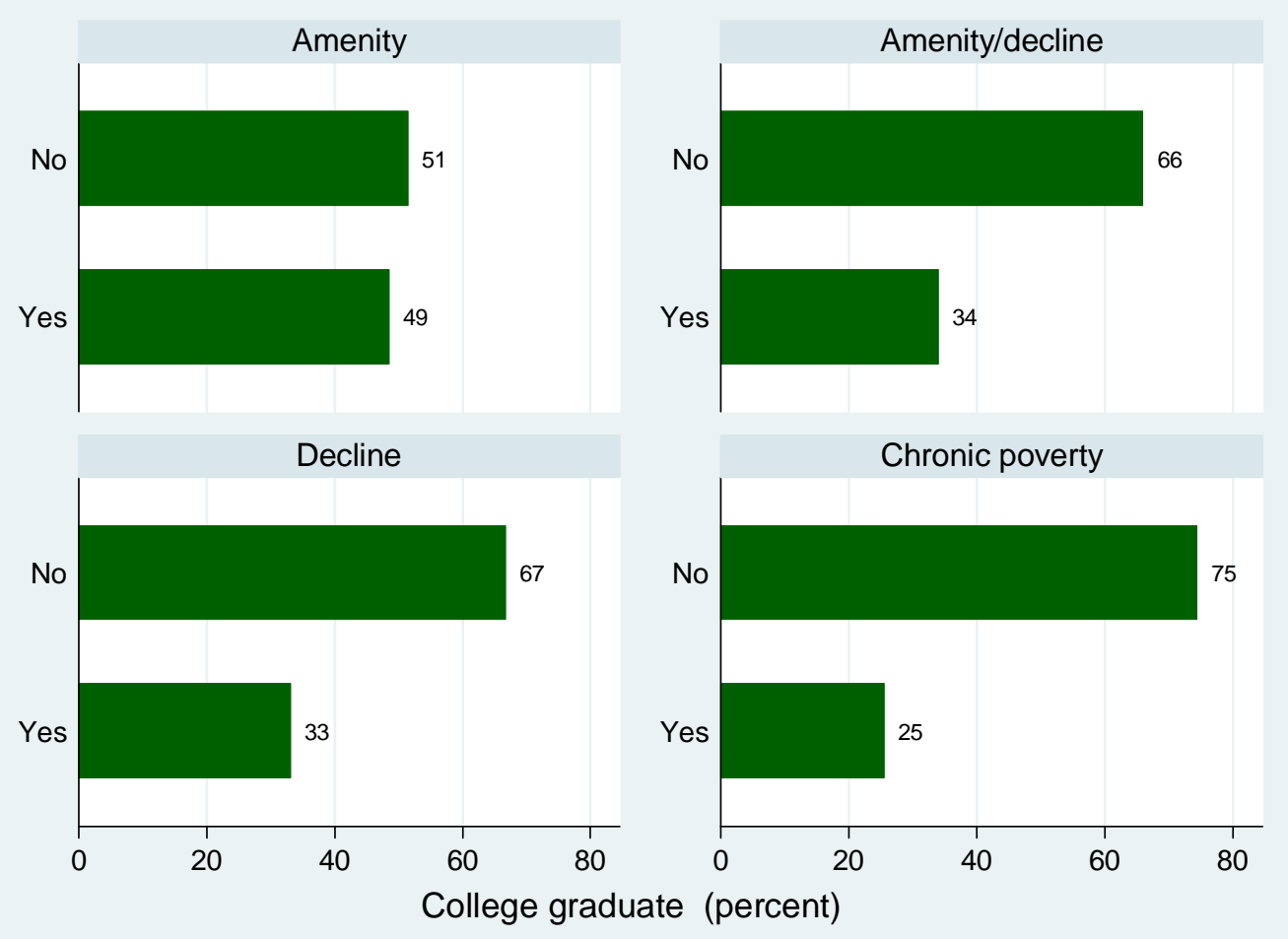




\section{While fathers far less likely to have a high school degree in chronically poor areas}

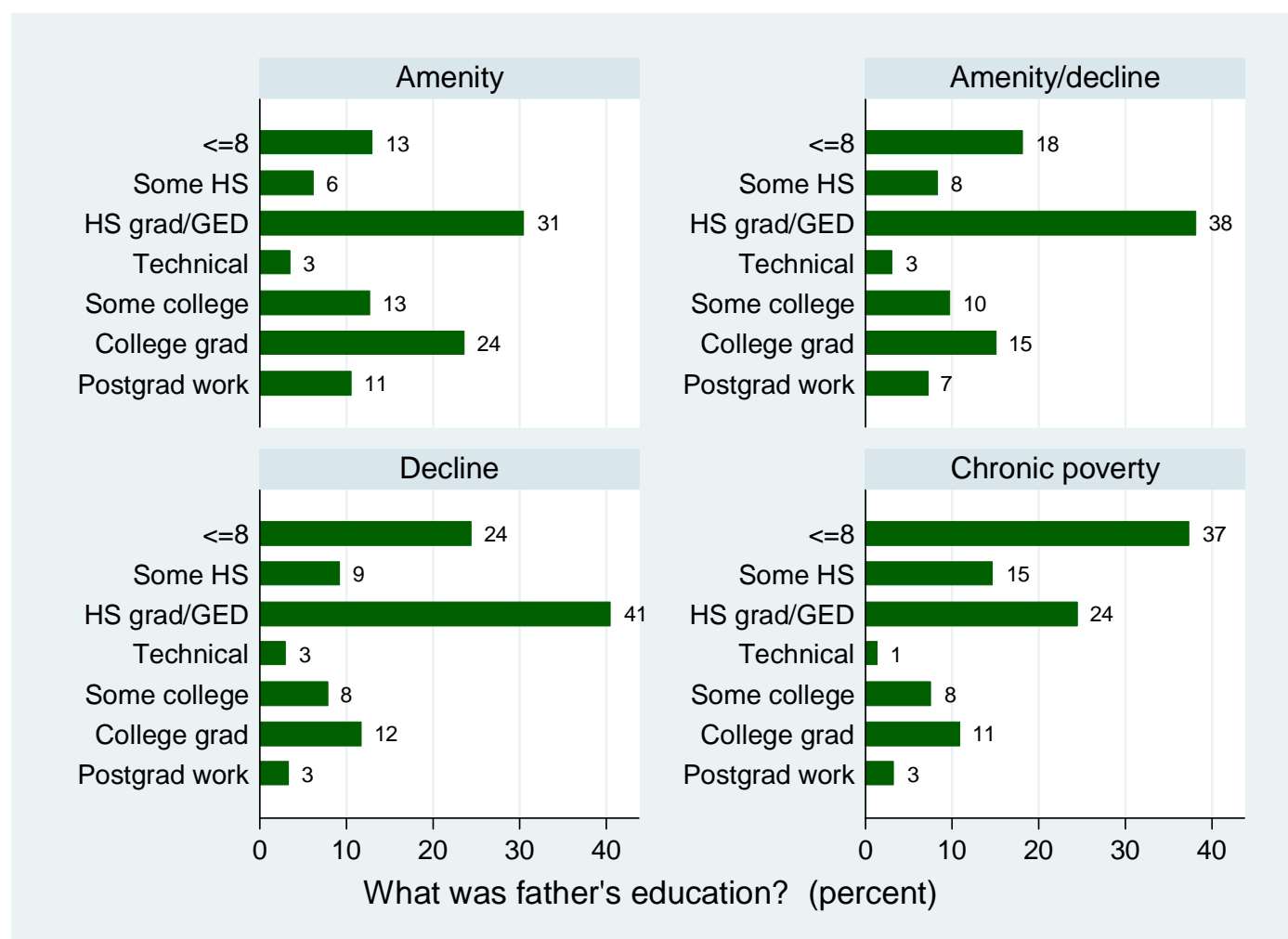




\section{Around $40 \%$ work full time, $20 \%$ are retired; self employment varies}

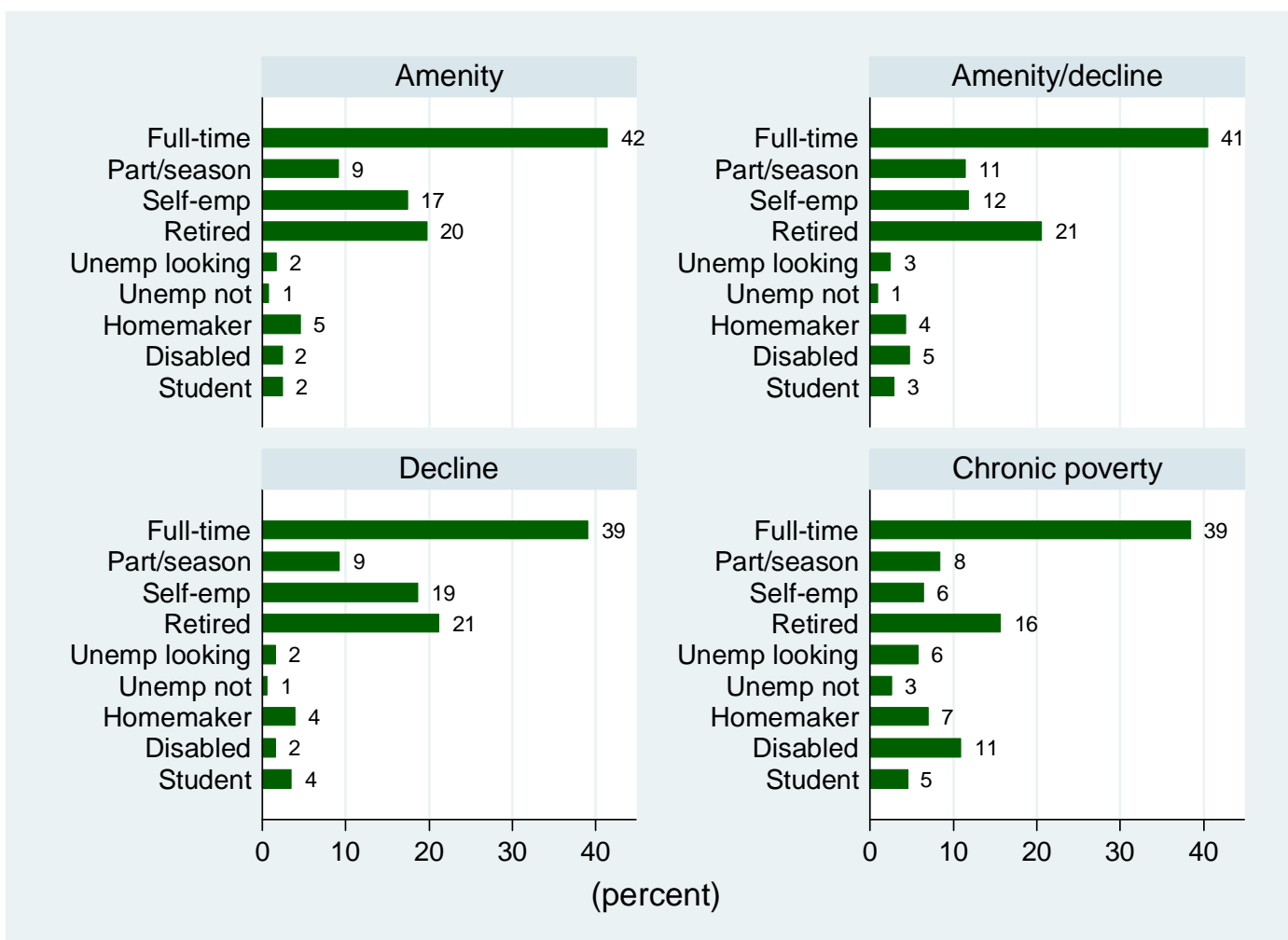




\section{Many rural Americans work 2 jobs, especially in the Midwest}
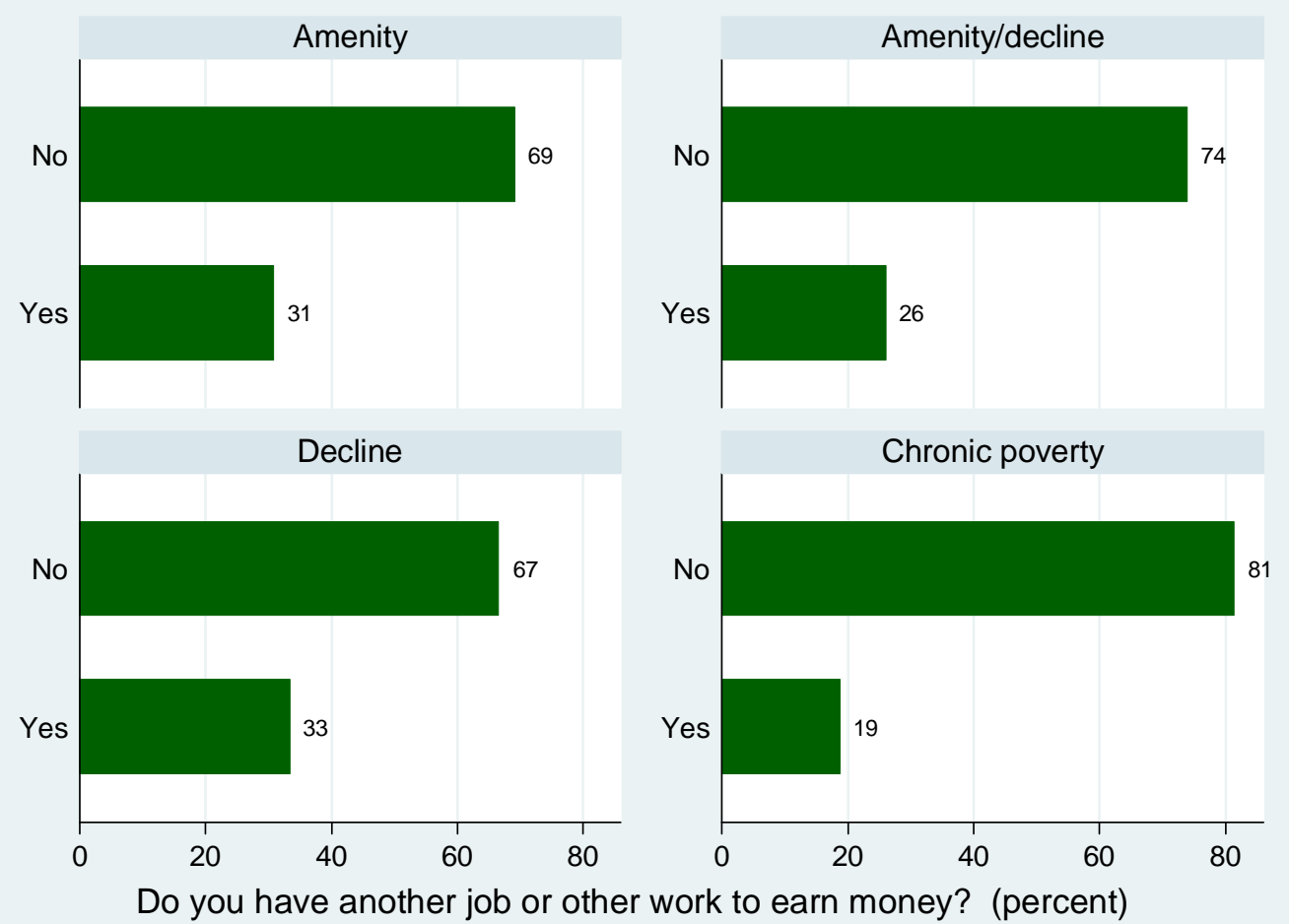


\section{Severe economic dislocation since 2000 affects the poor \& transitioning places most}

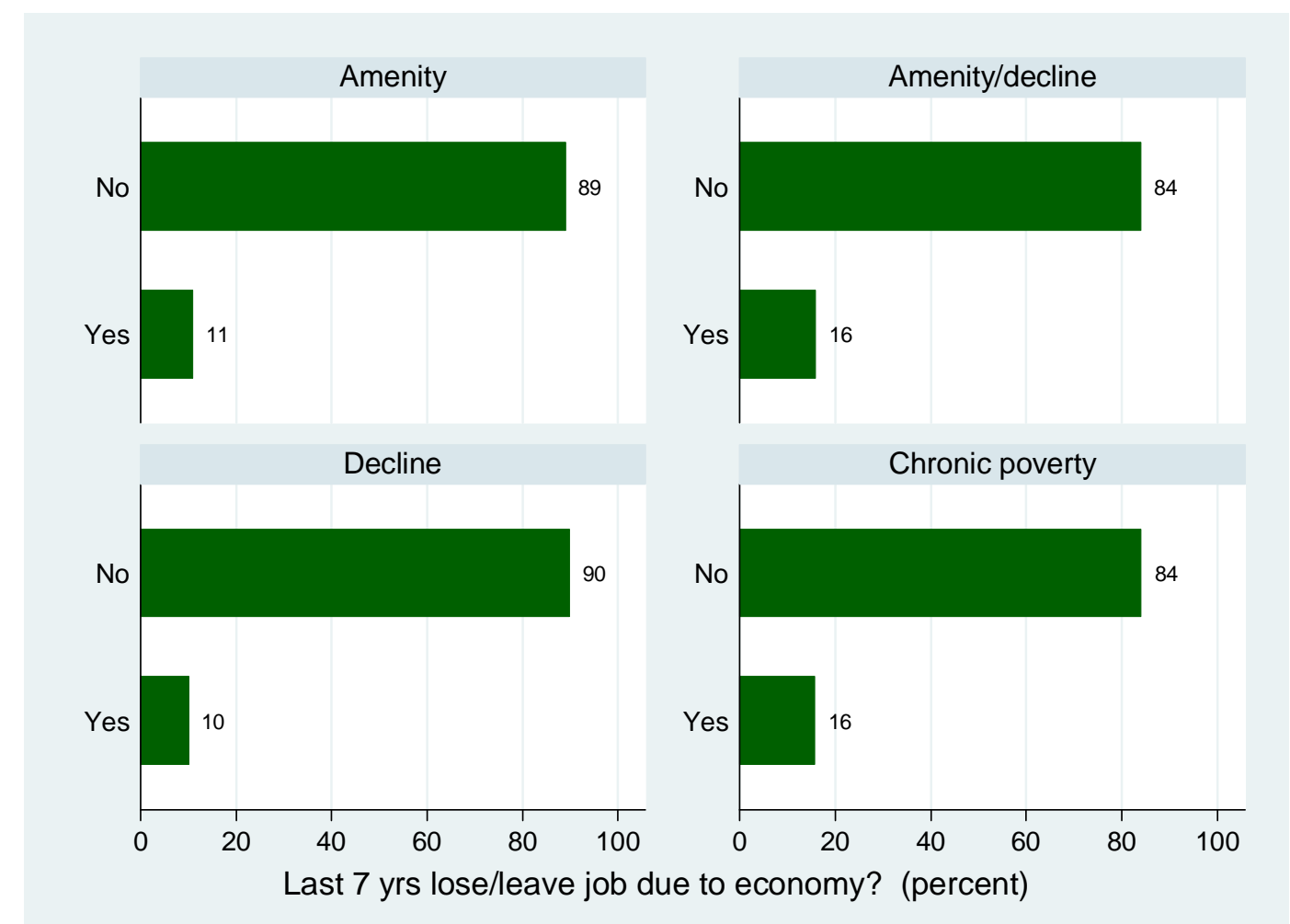




\section{Low food stamp use in Midwest}
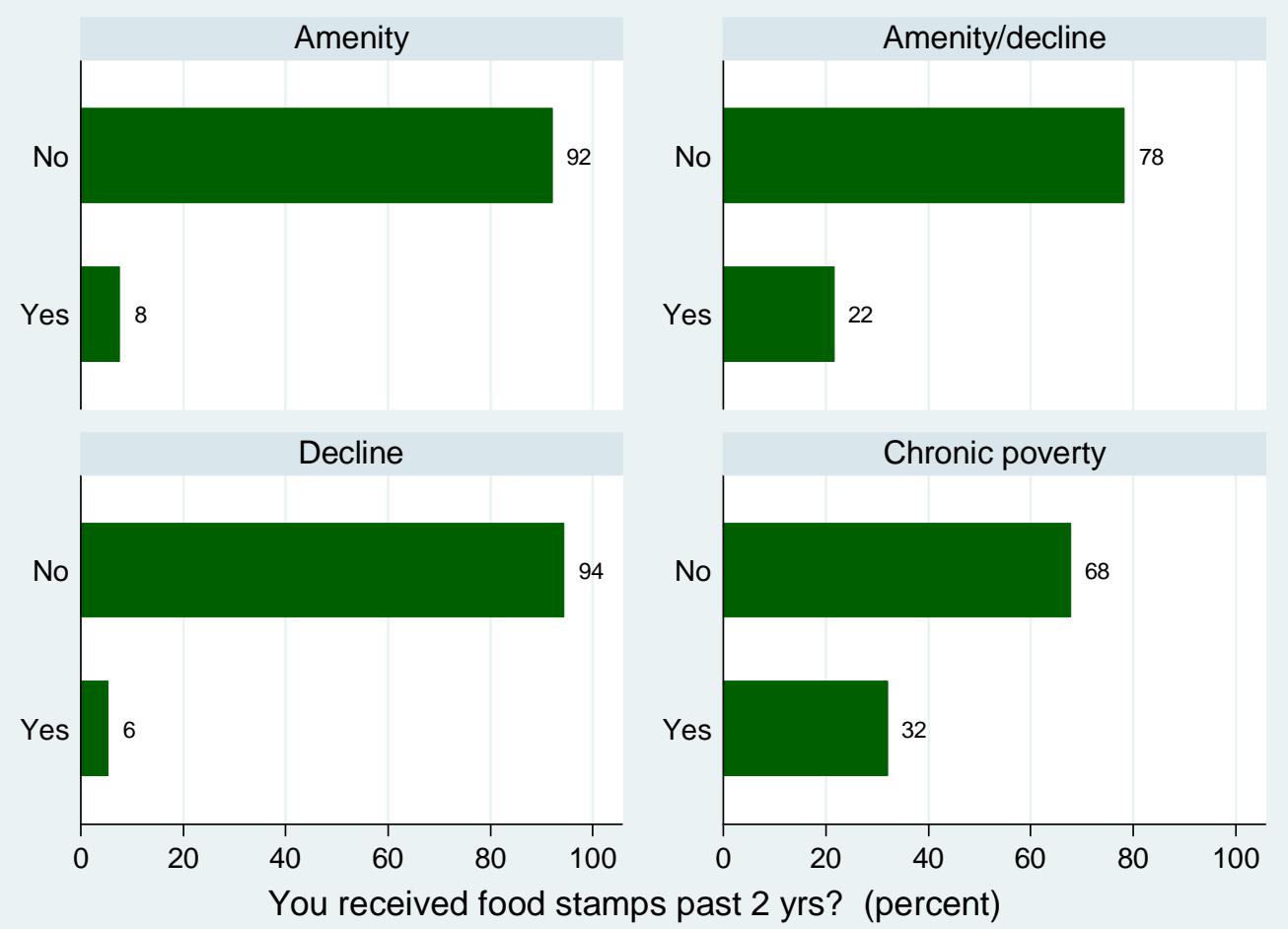


\section{Everywhere adults think young people need to leave for opportunity}

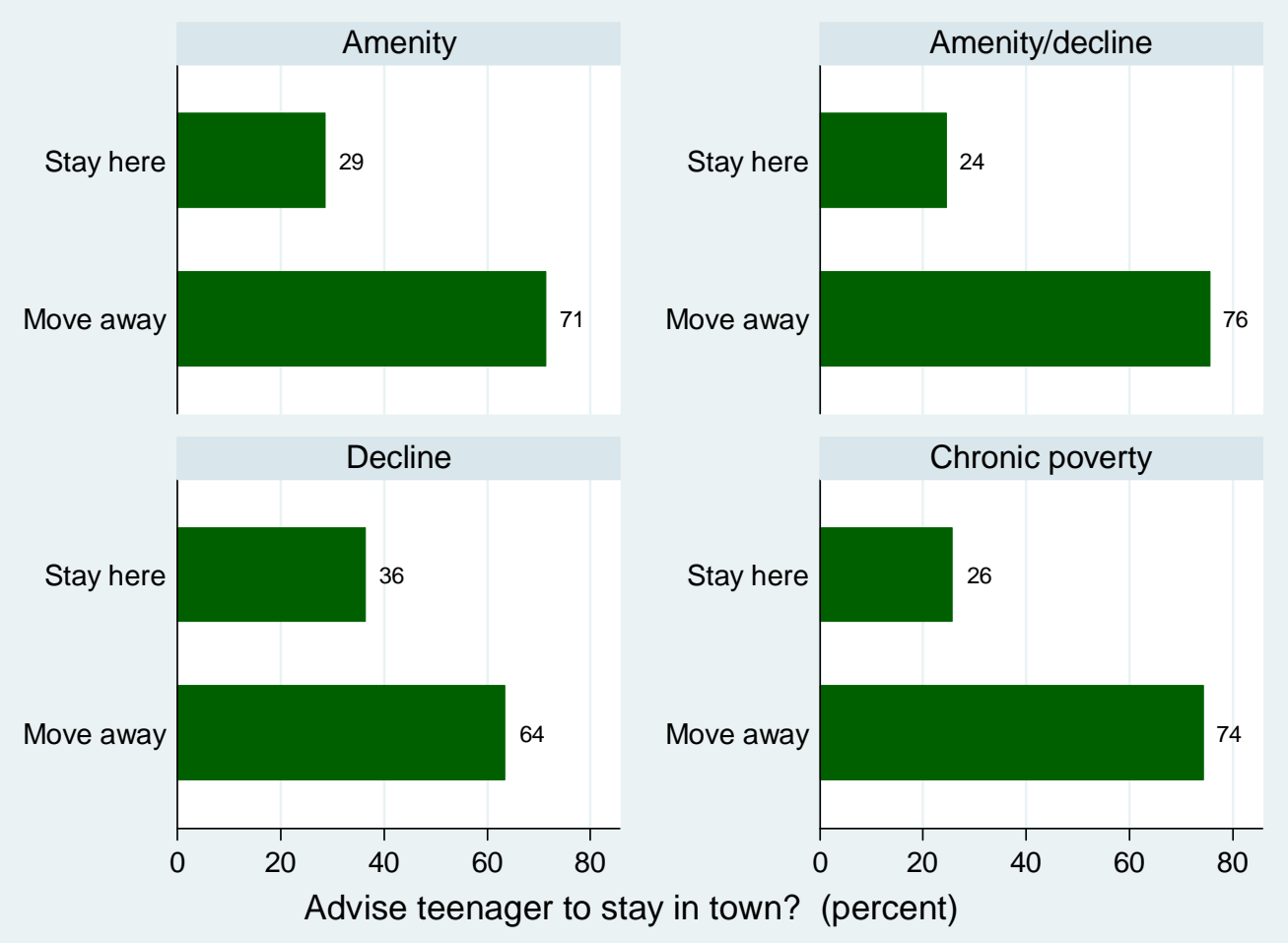


The wars in Iraq and Afghanistan touch rural Americans - when young people seek opportunity

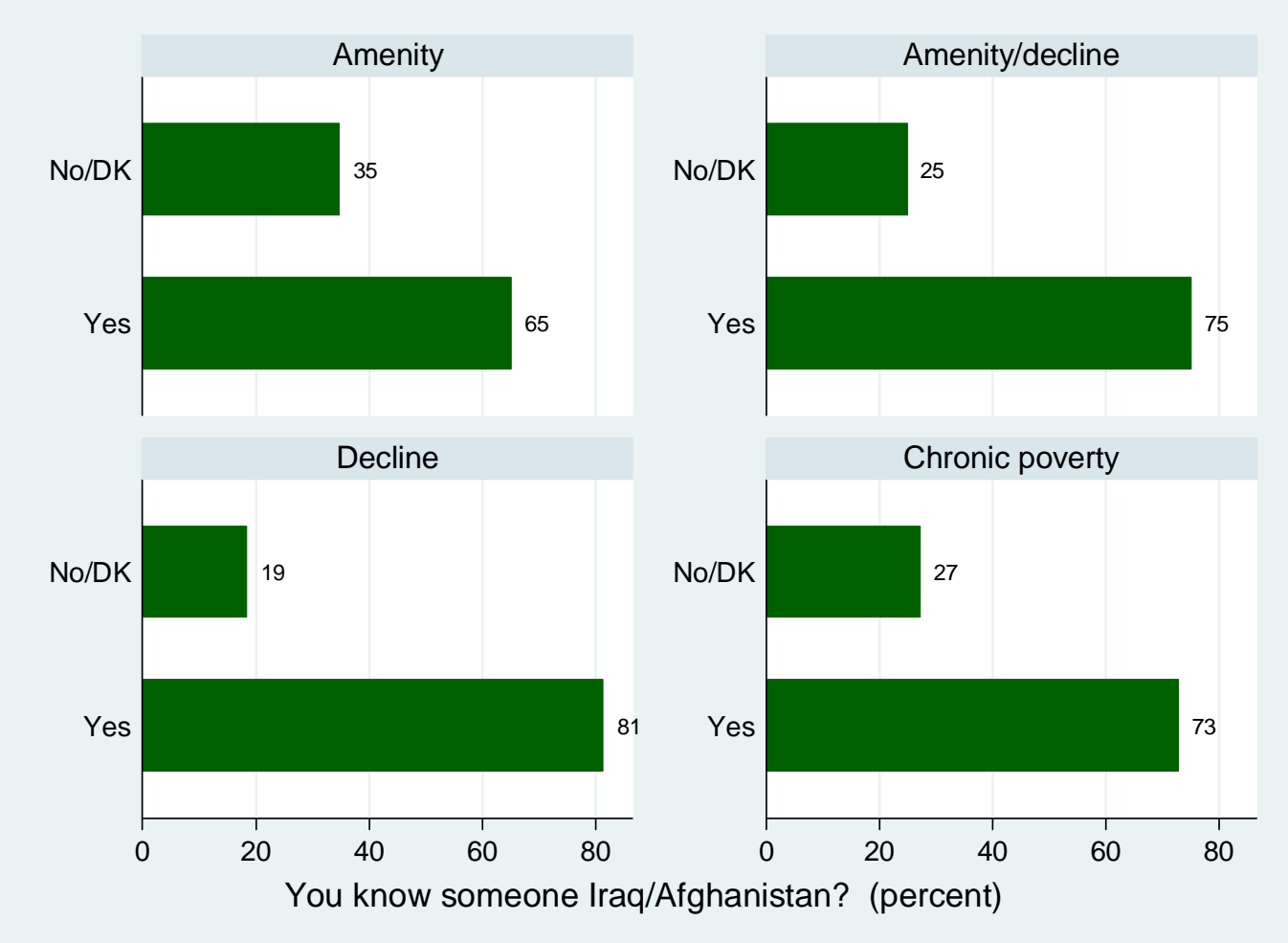




\section{Lots of newcomers in amenity areas}

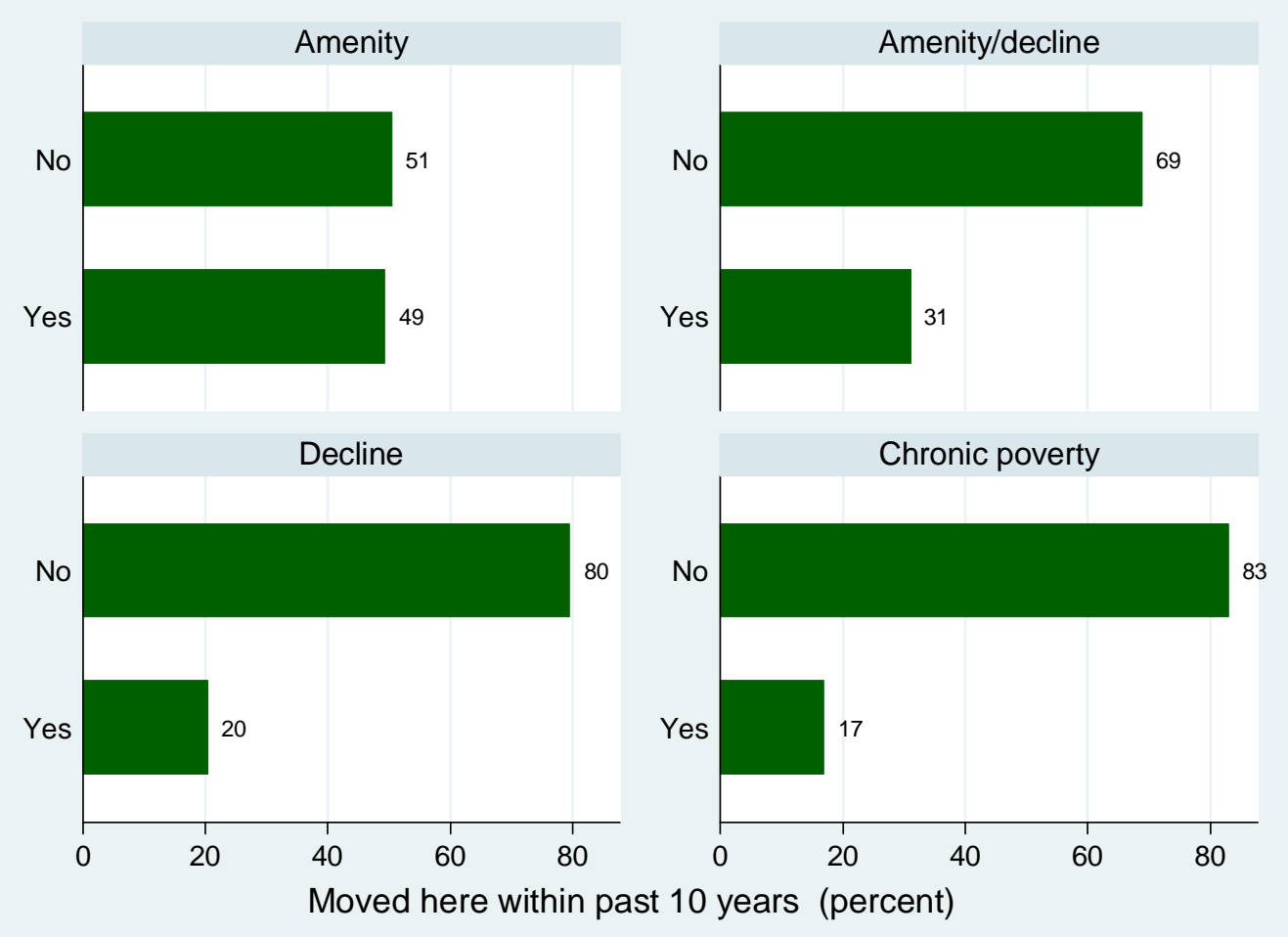




\section{Roots run deep in the declining and the poor areas}

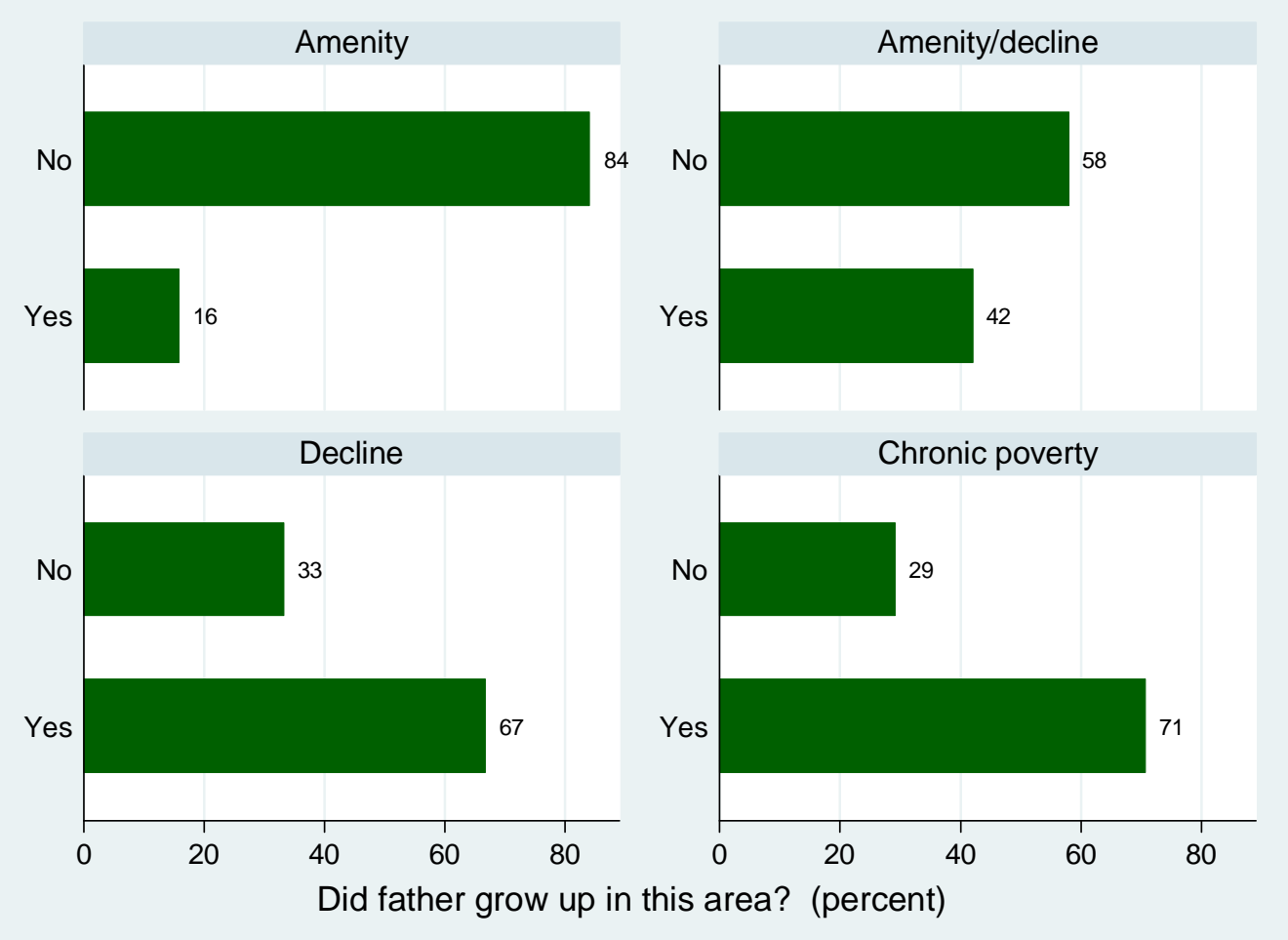




\section{Amenity area folks value natural beauty}

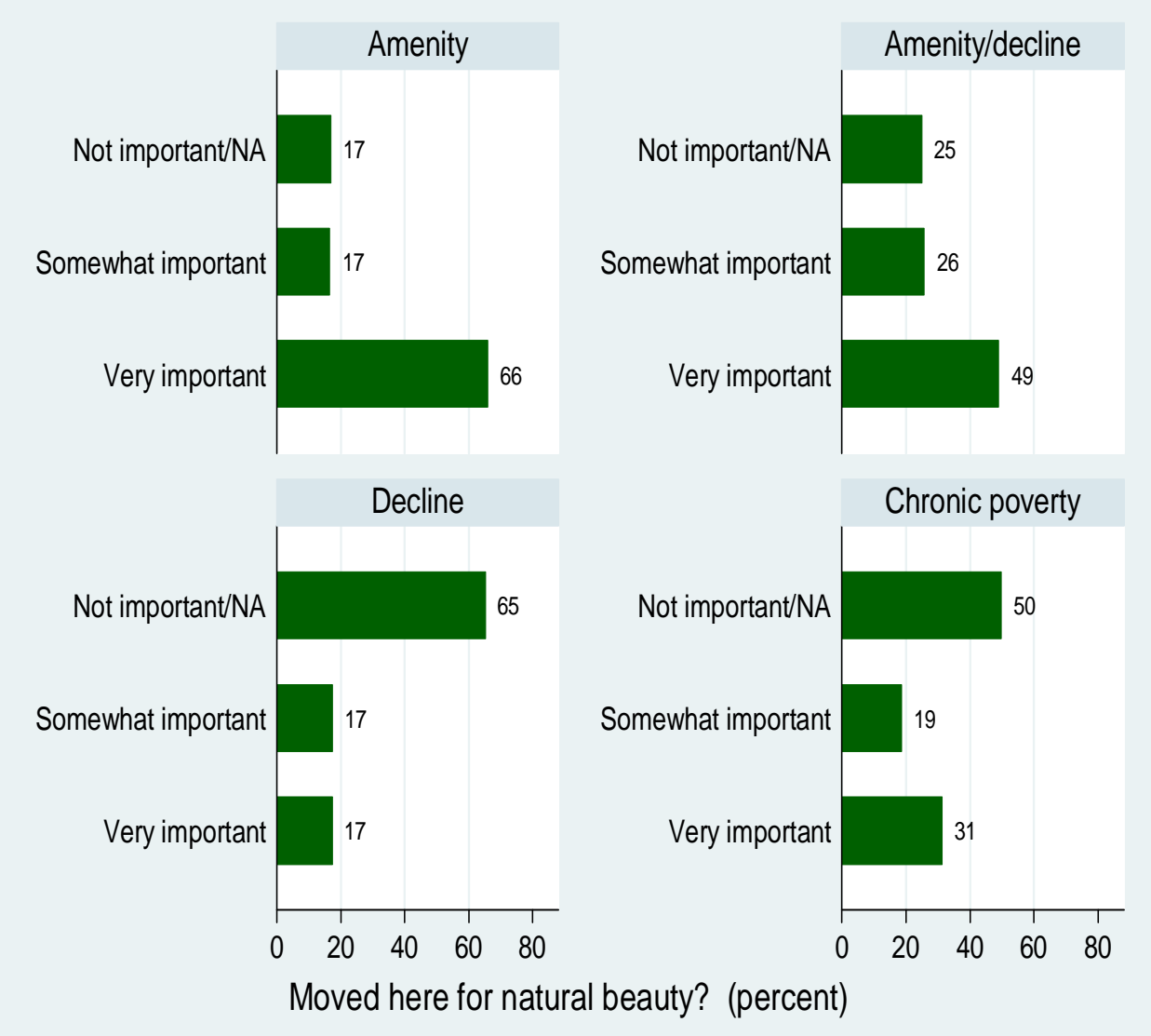




\section{And worry about sprawl and development}

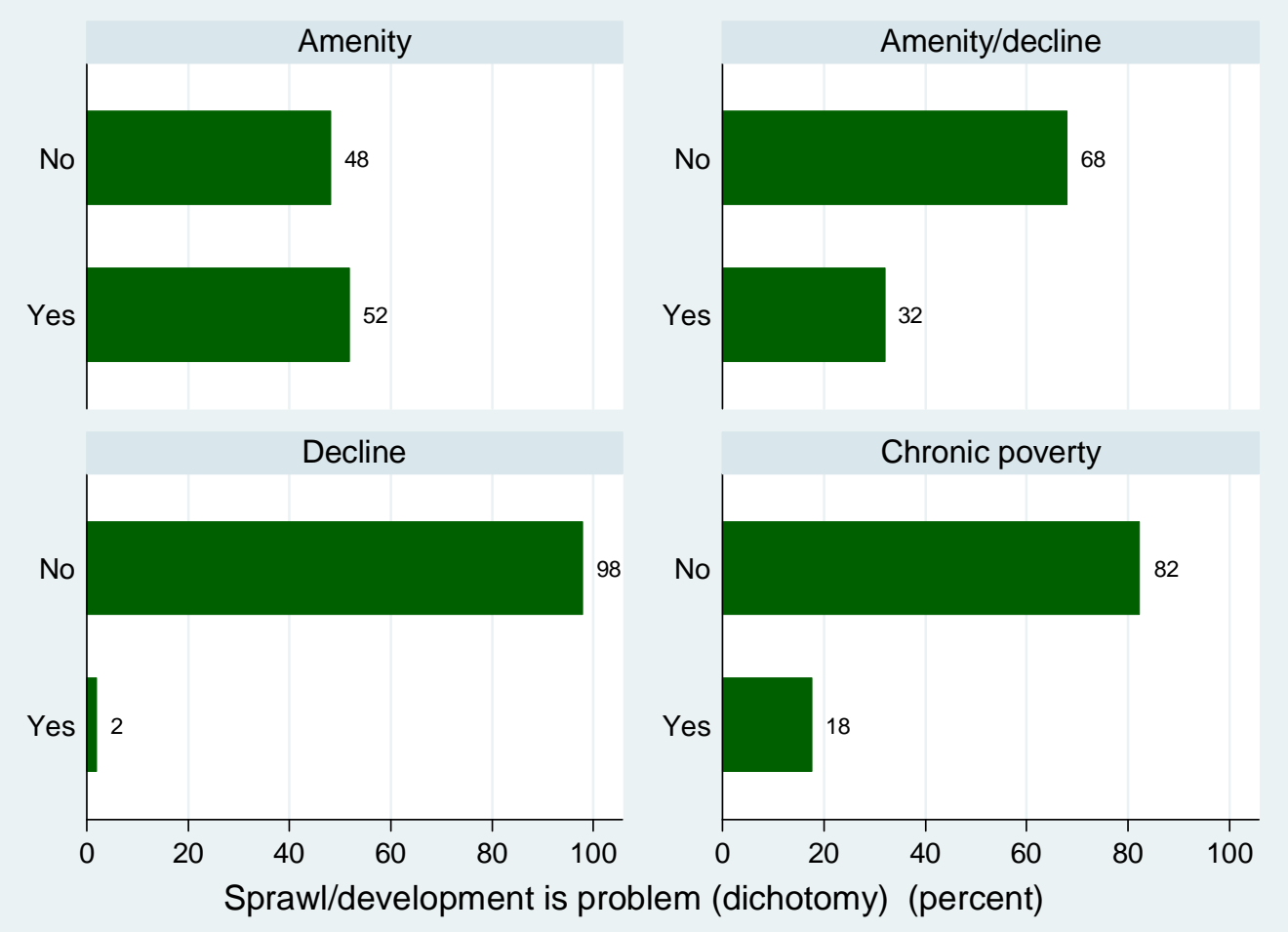




\section{Amenity area residents value conservation rules}

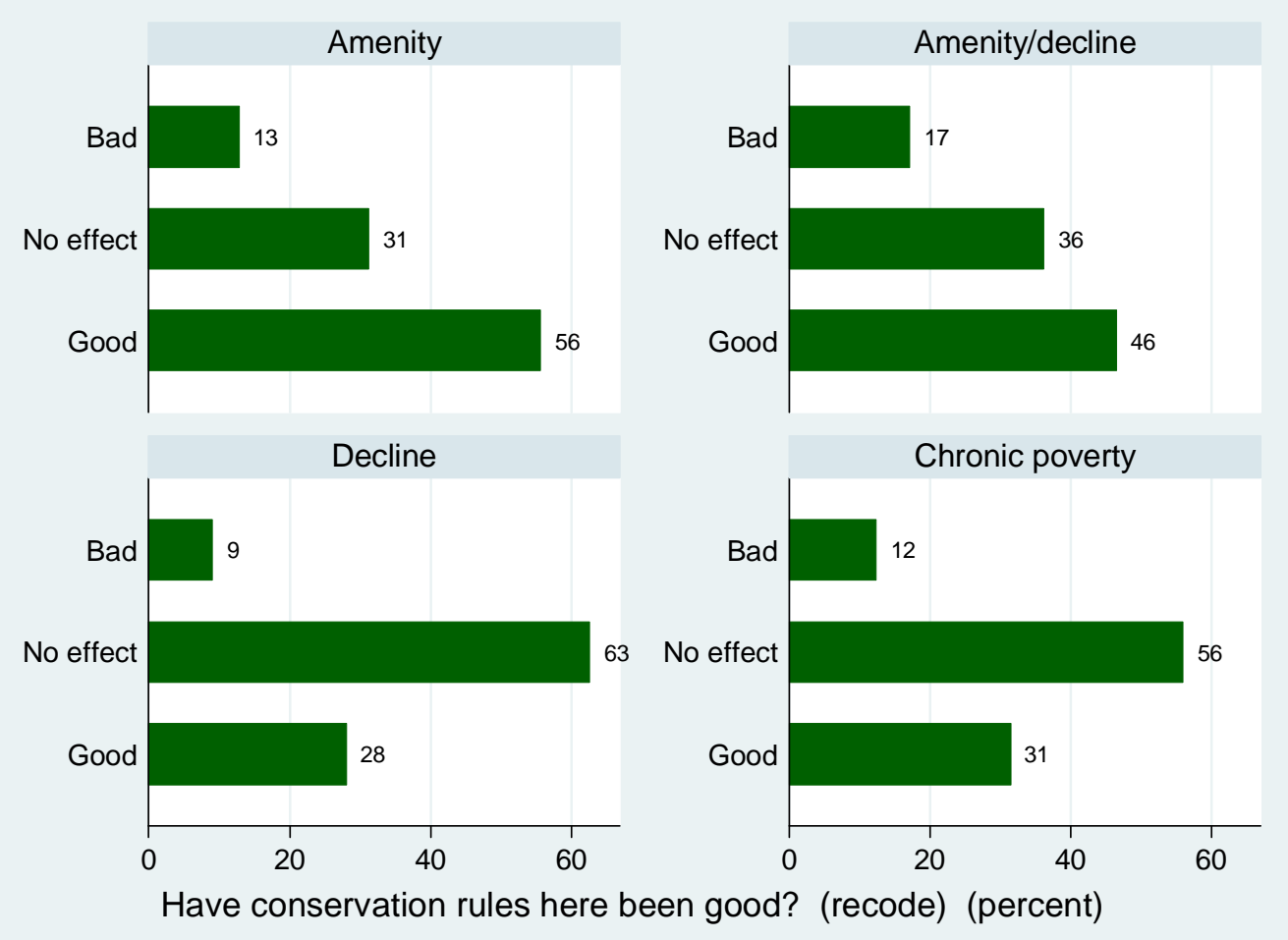




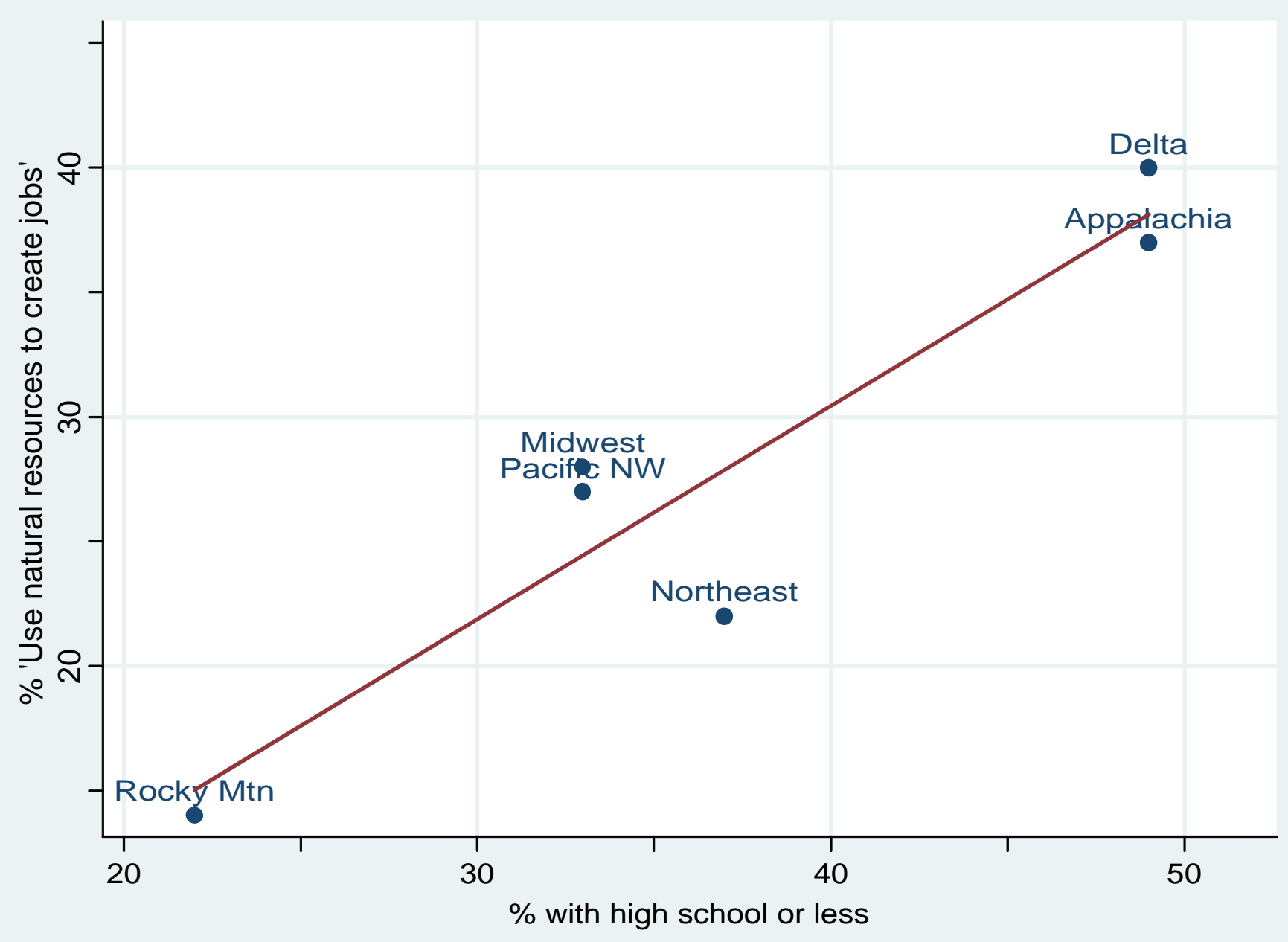




\section{Concern about housing affordability goes with growth and with poverty}

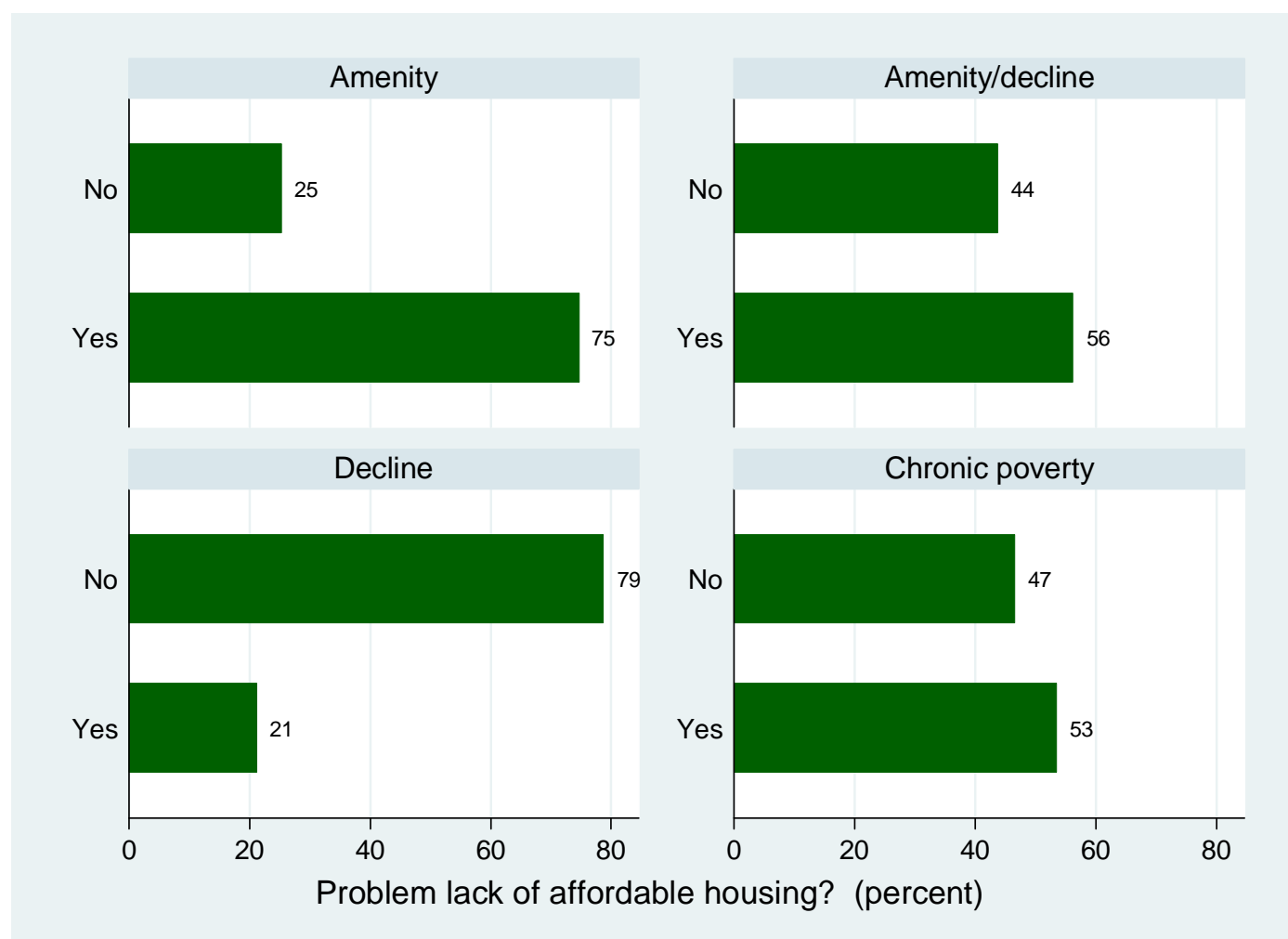




\section{Lack of recreational opportunities a problem in poor areas}
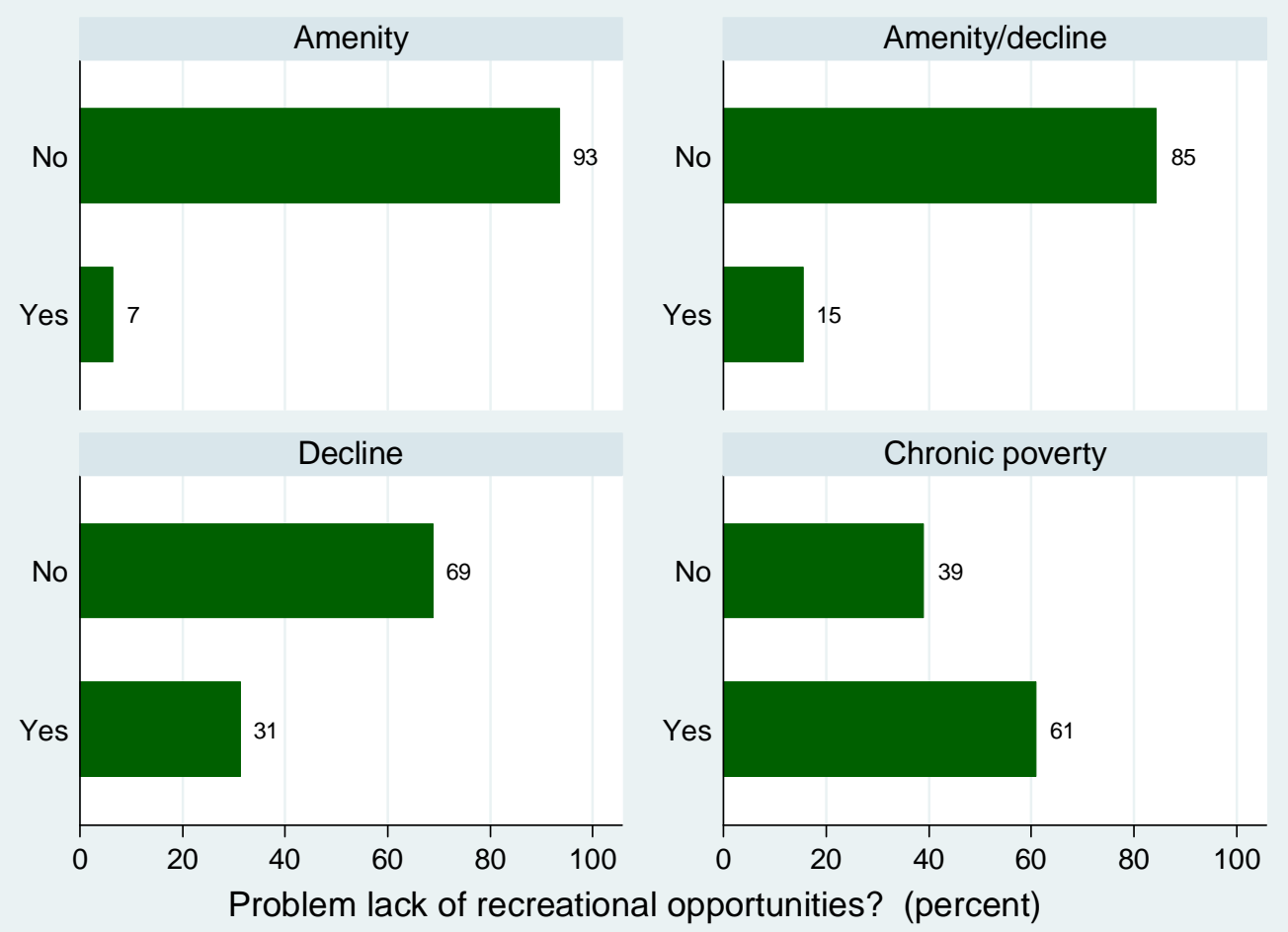


\section{Lack of health and social services a problem in poor areas}

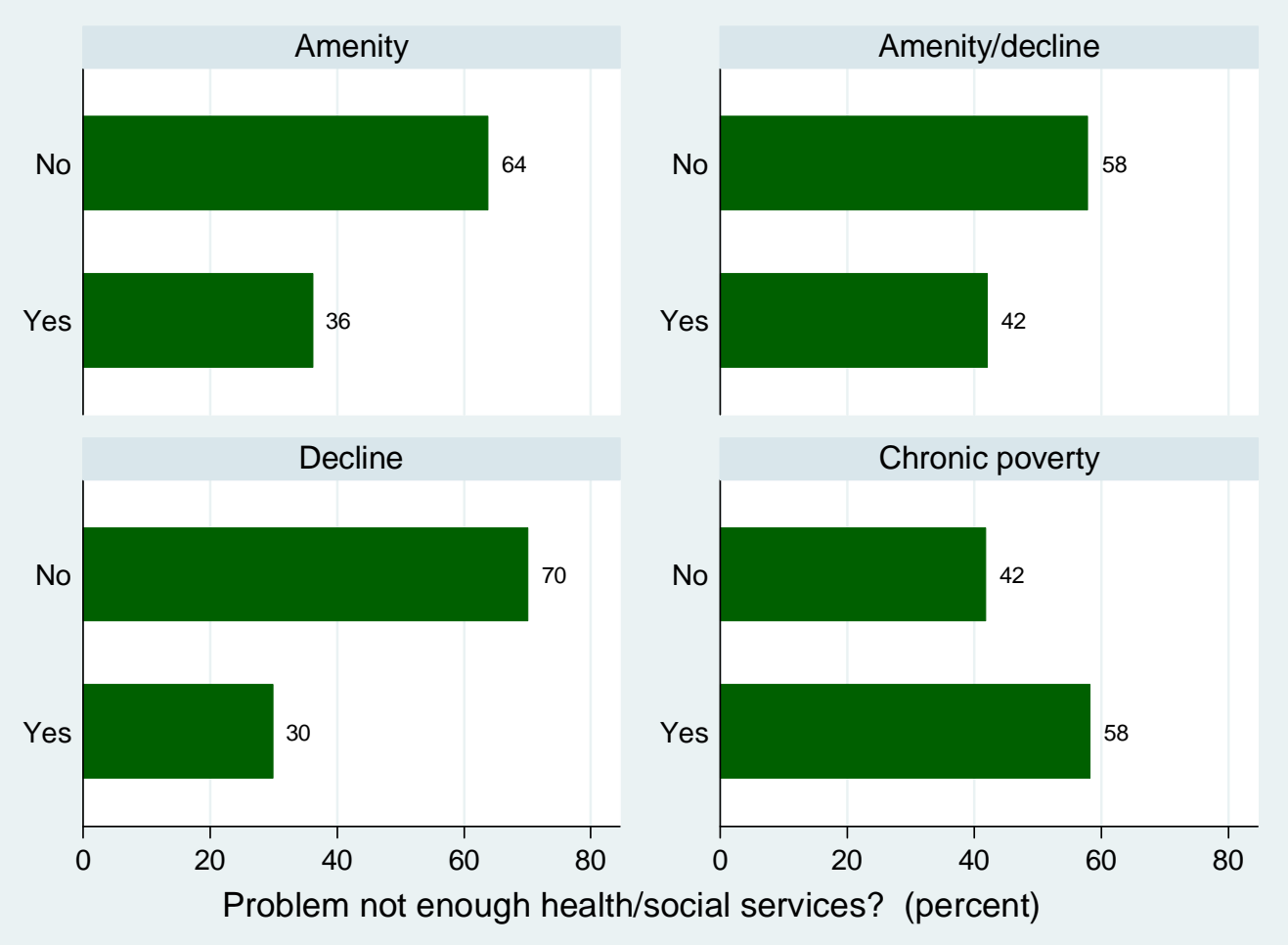




\section{Drugs concern everyone, but especially those in poor areas}
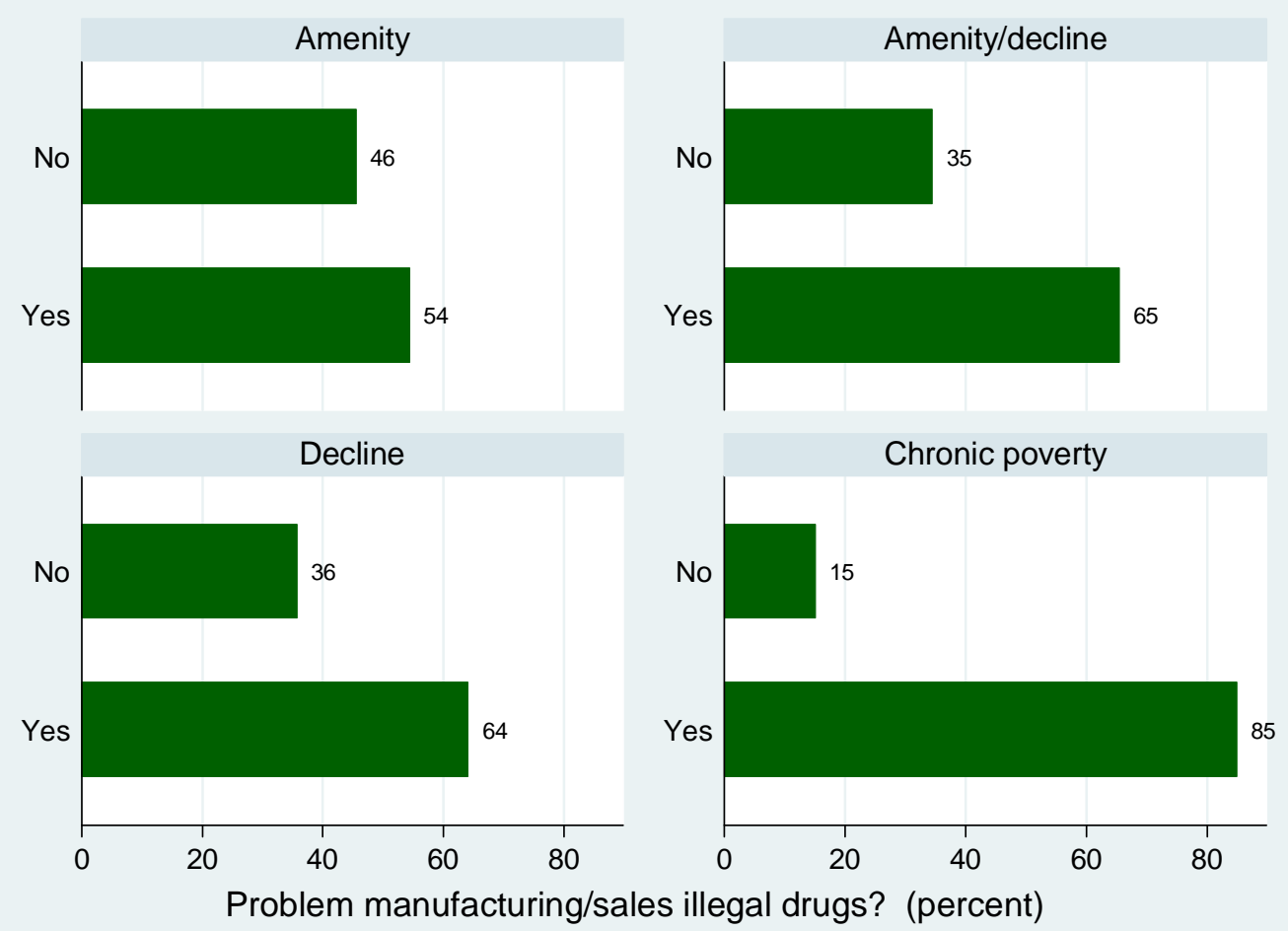


\section{Family structure varies by type of region - a smaller percent are married in poor places}

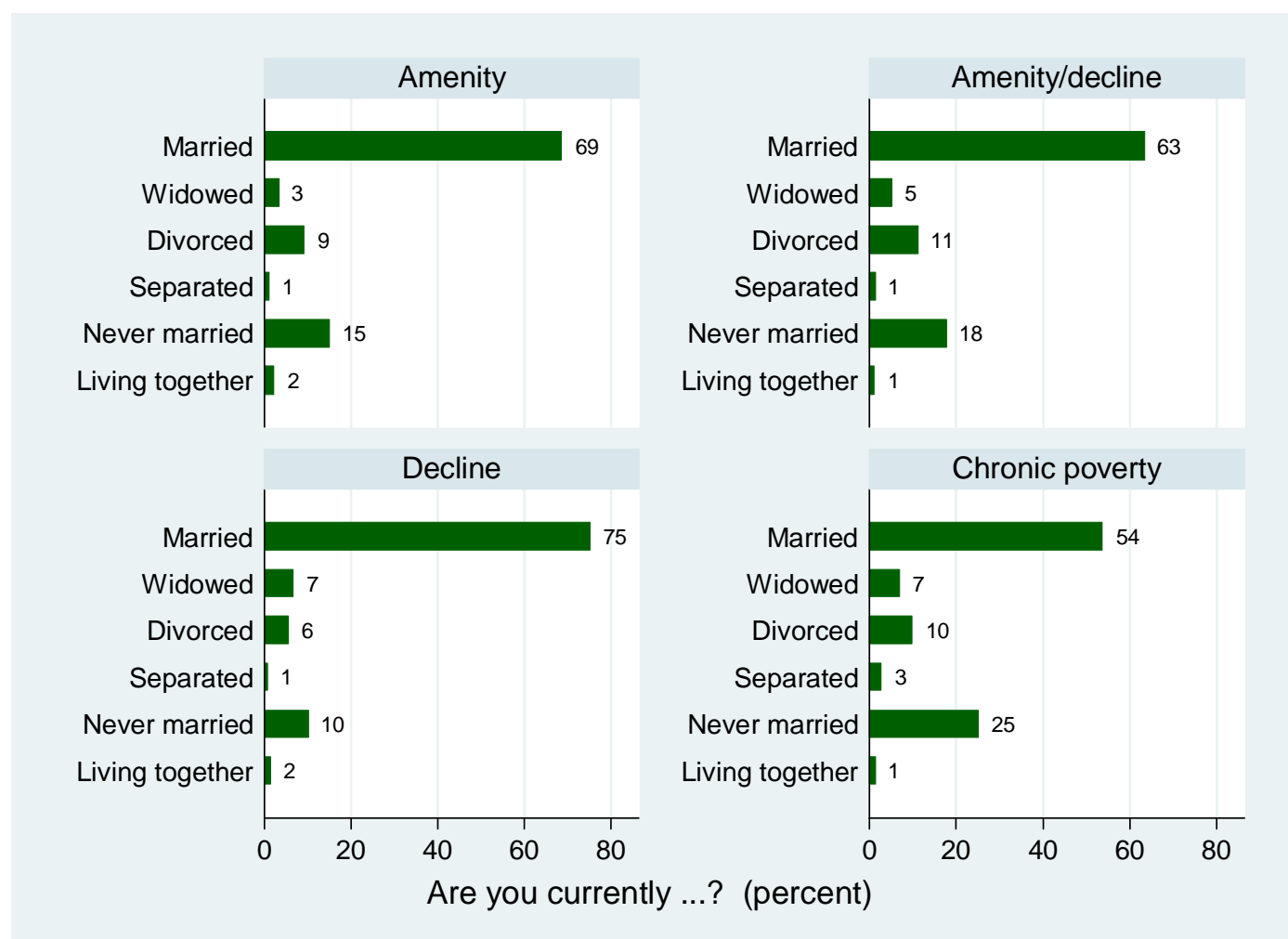




\section{Born again Christians are prevalent in poor areas}
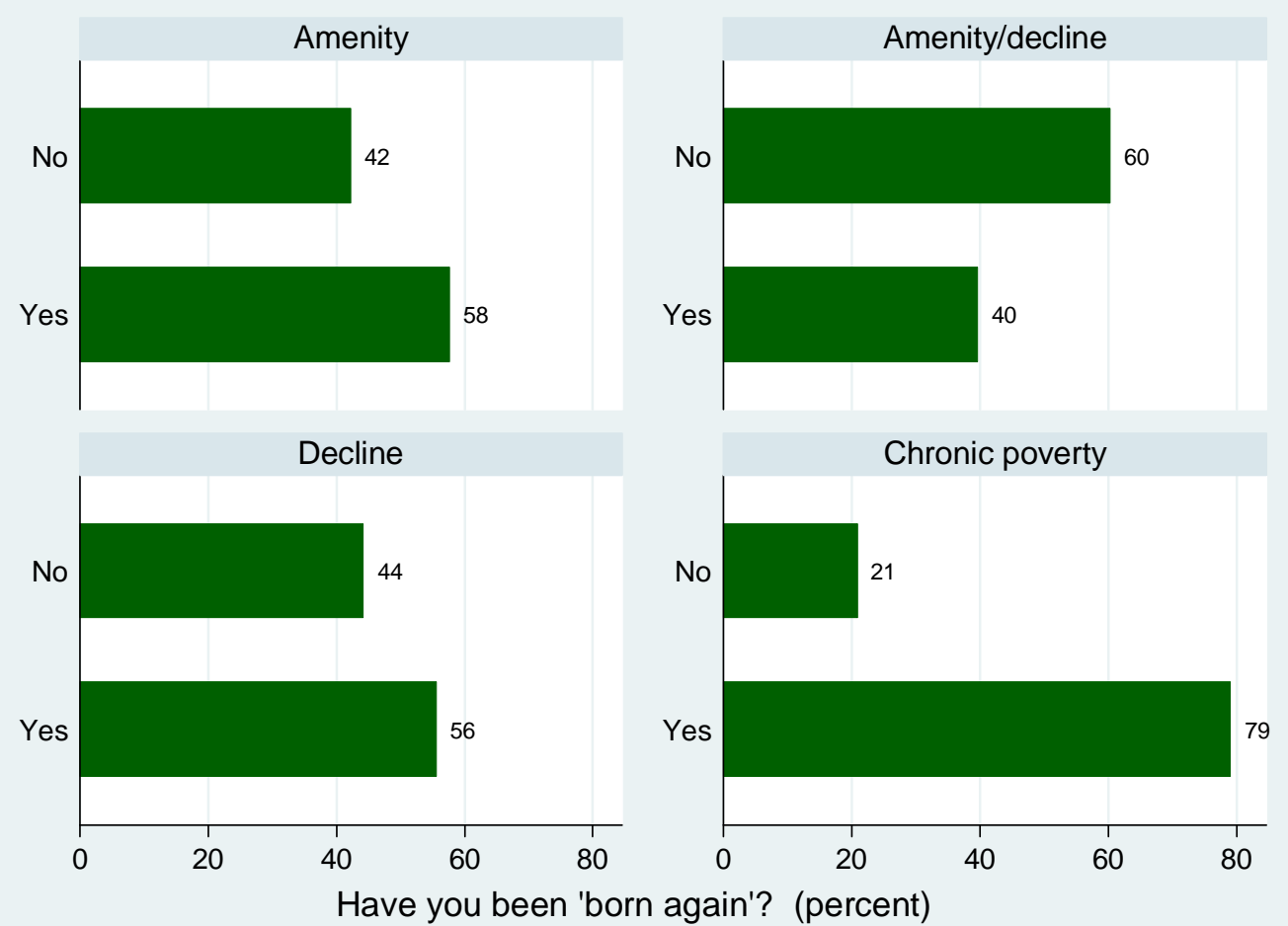


\section{Blue and red politics in rural America vary by region}

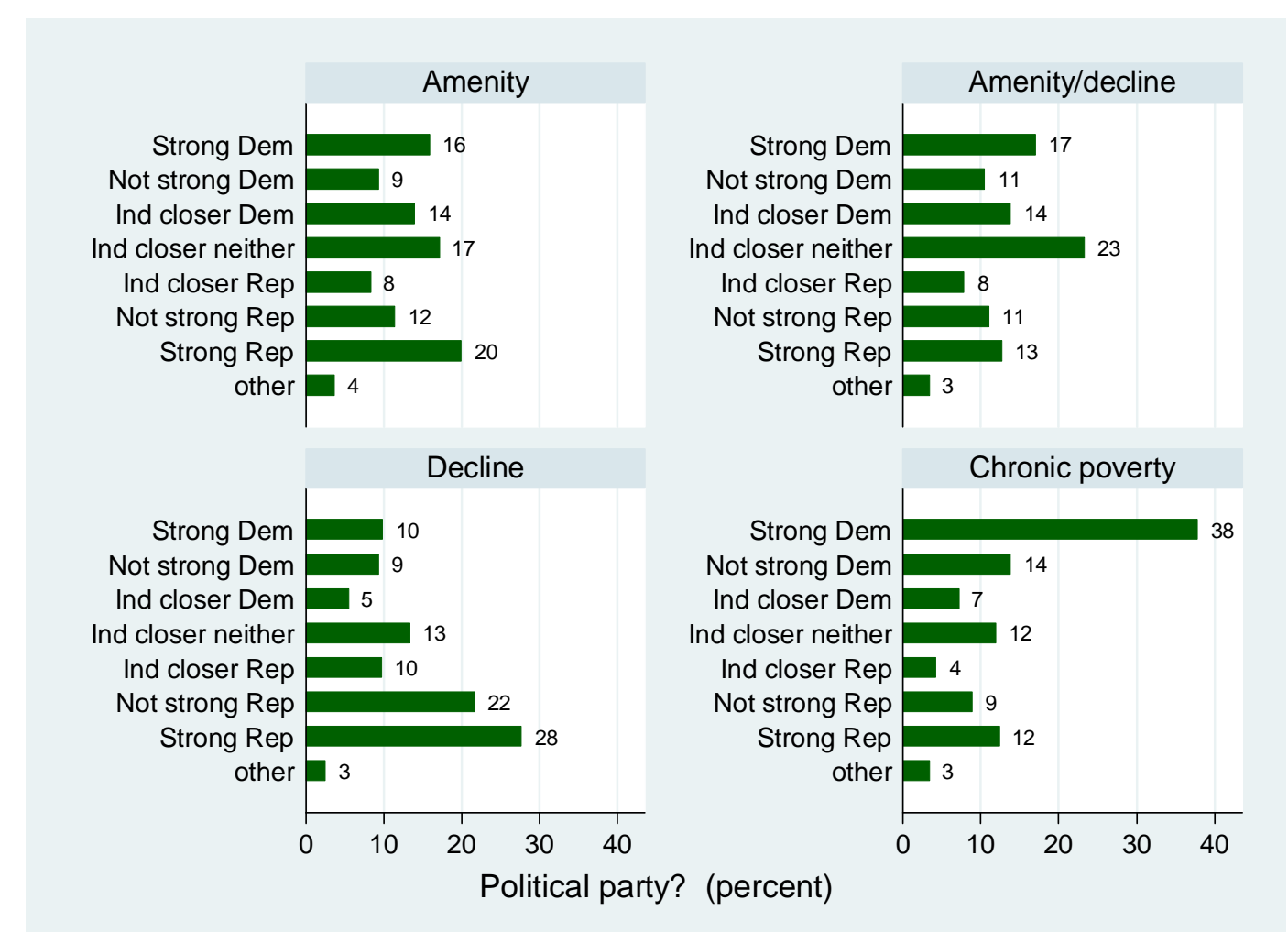




\section{Trust is highest in everywhere, especially in the Midwest, lowest in poor places}

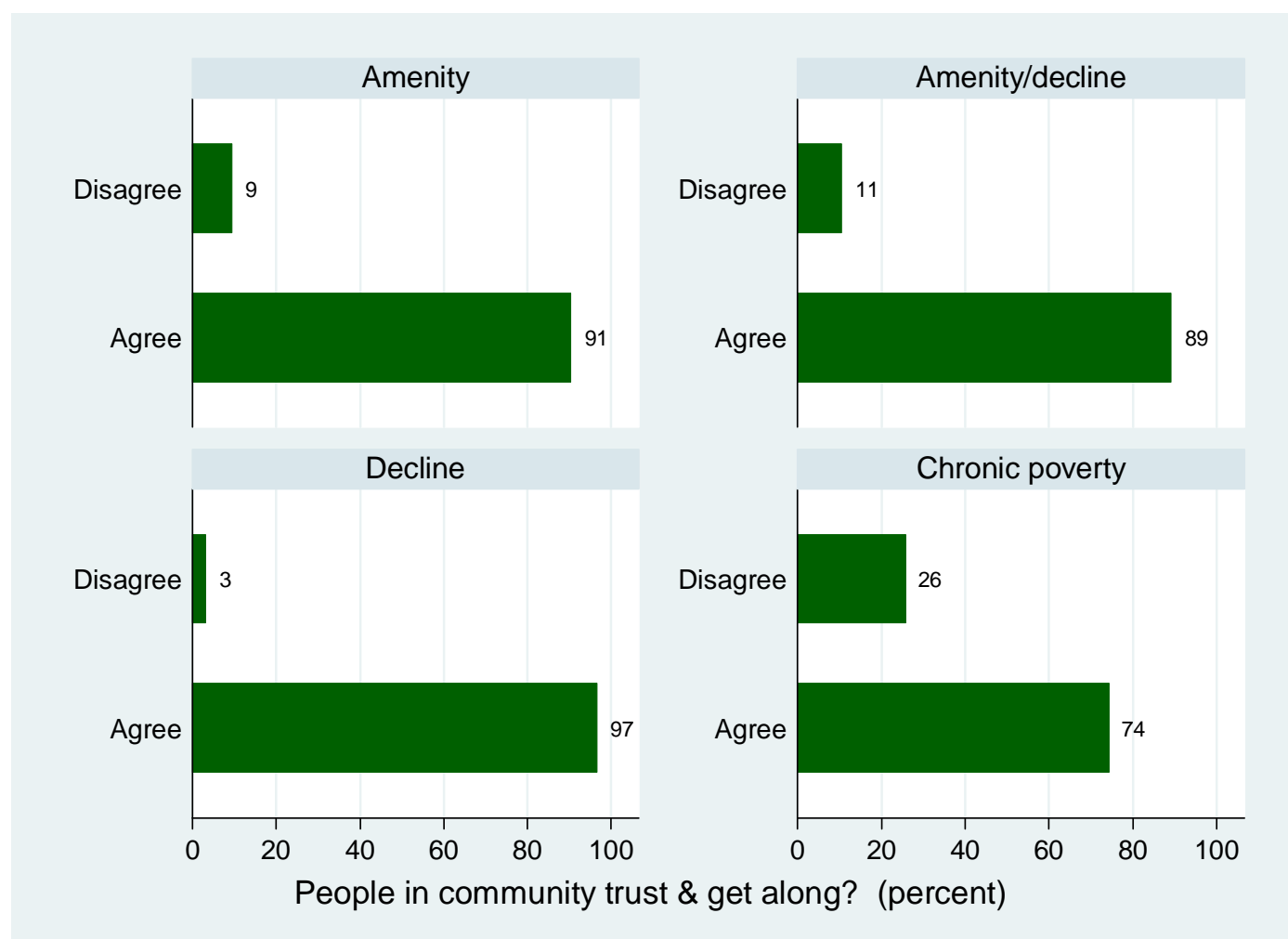




\section{Rural Americans are joiners, especially in the Midwest}

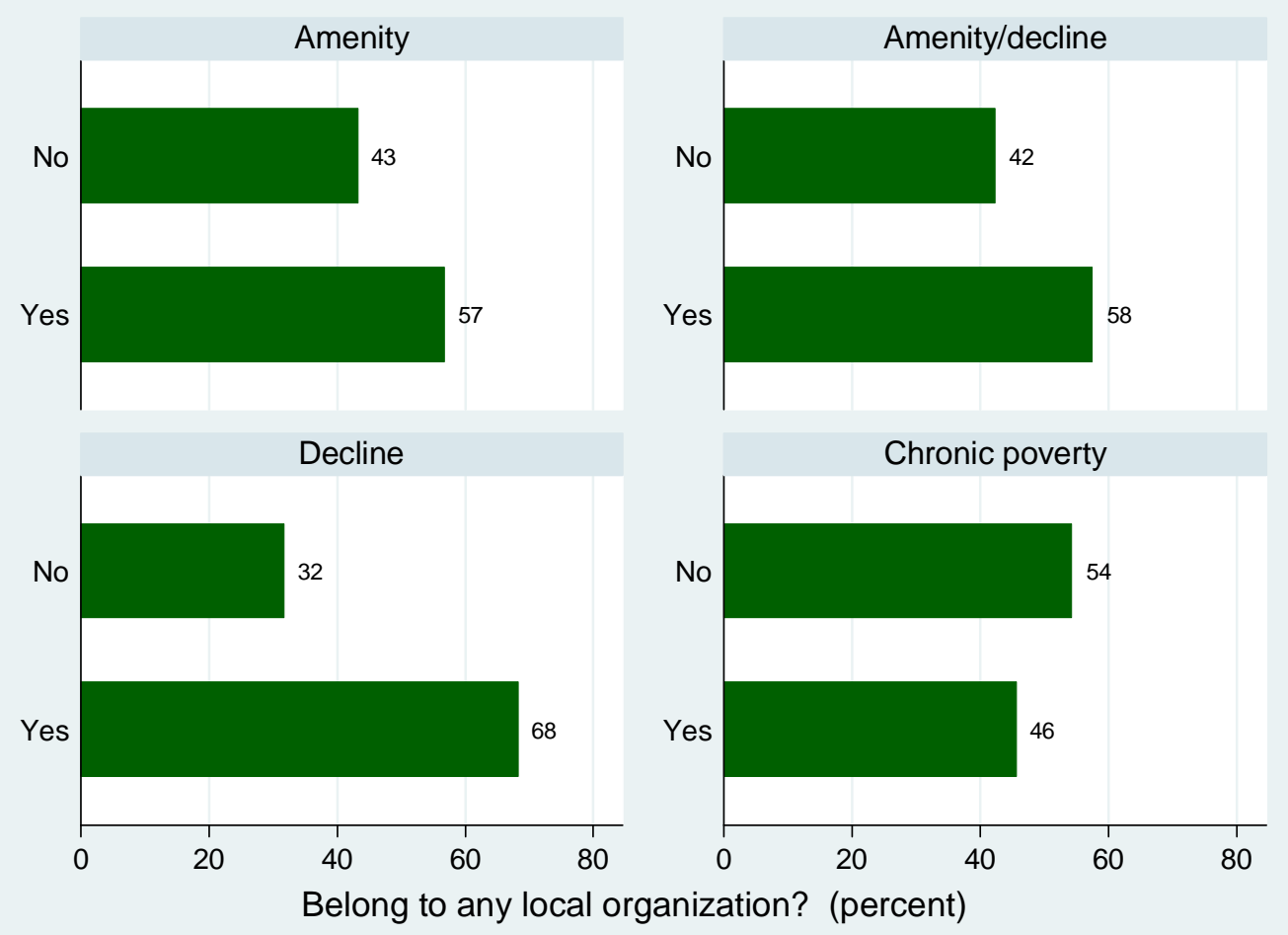




\section{People want to stay for natural beauty, especially in amenity areas}

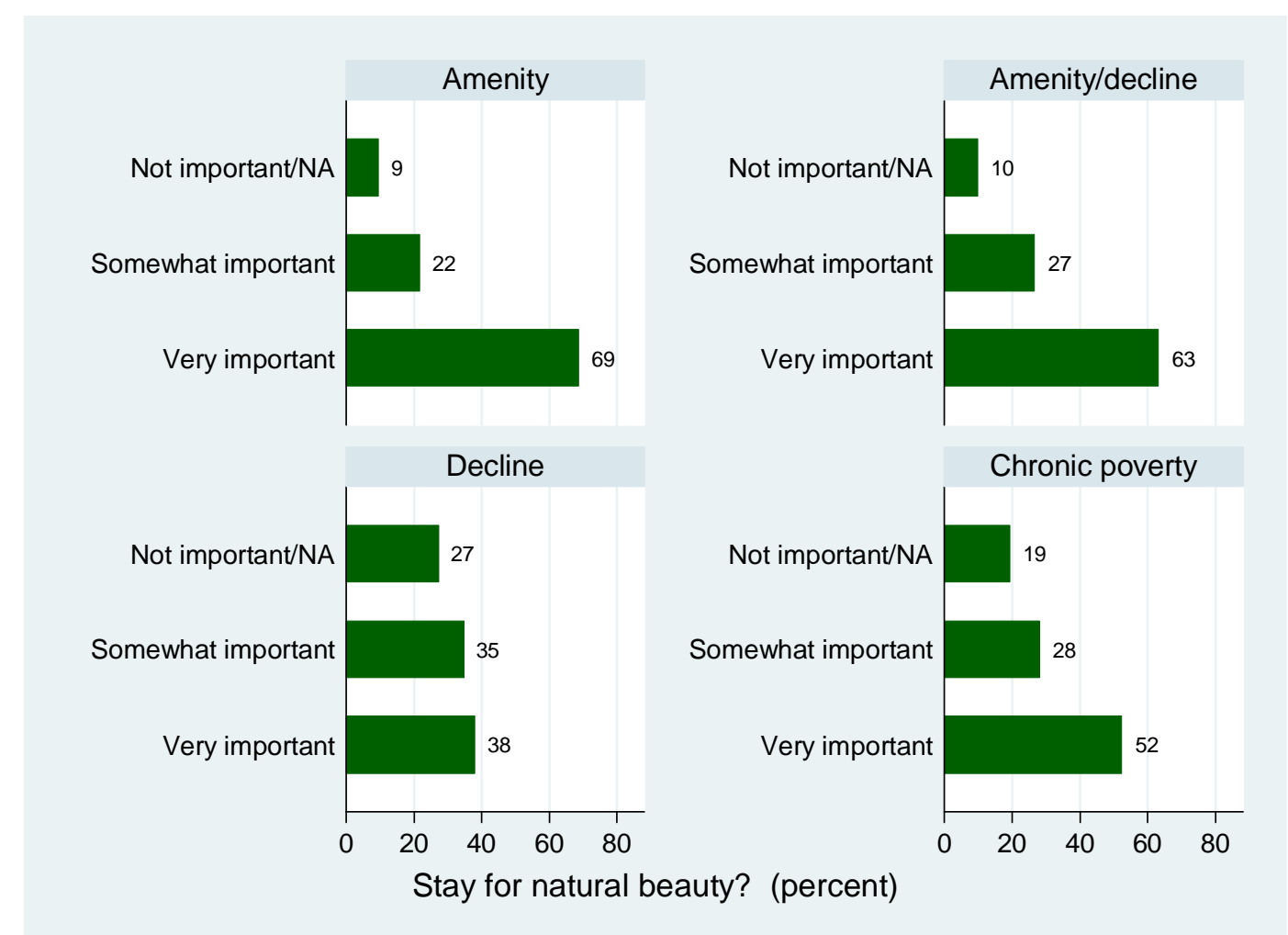




\section{And for many family is important}

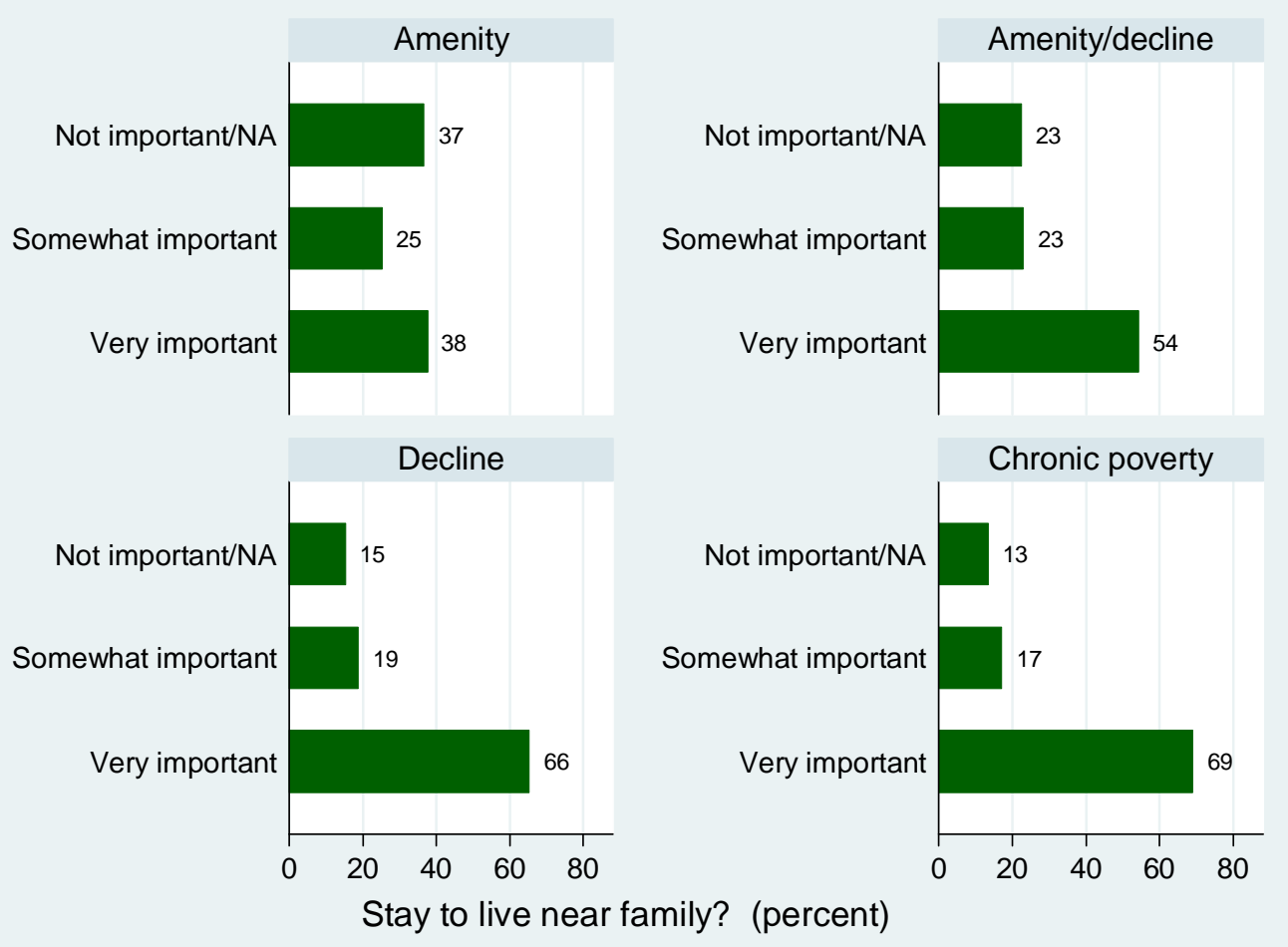




\section{Rural Americans enjoy the out of doors, though less in poor places}
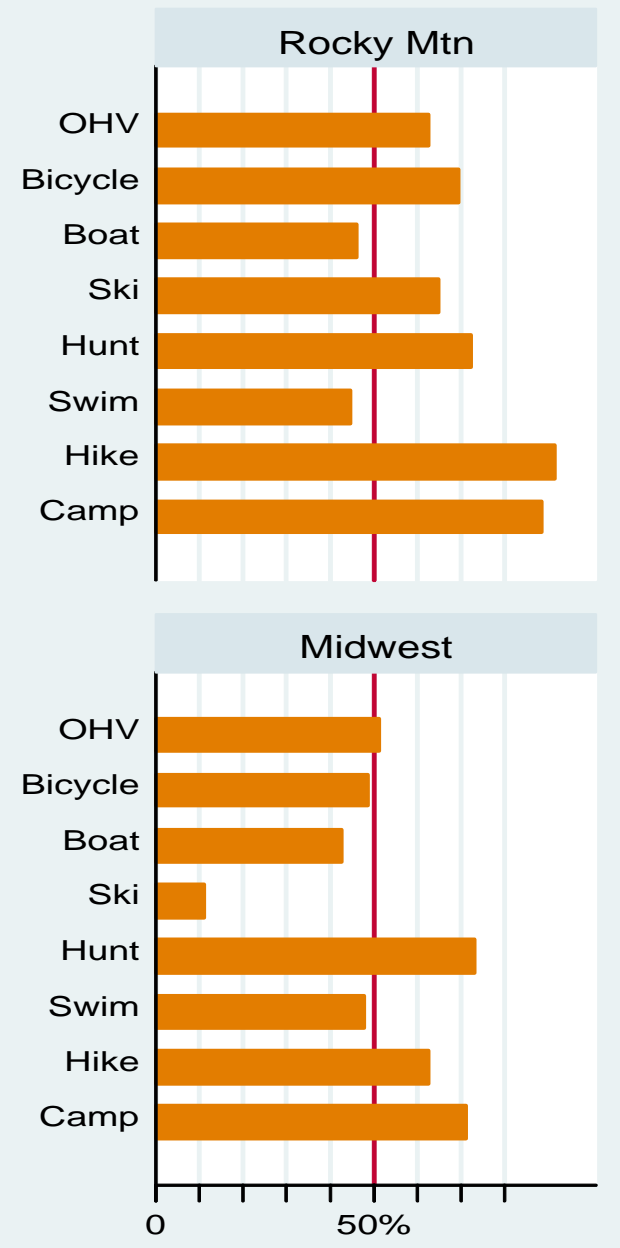
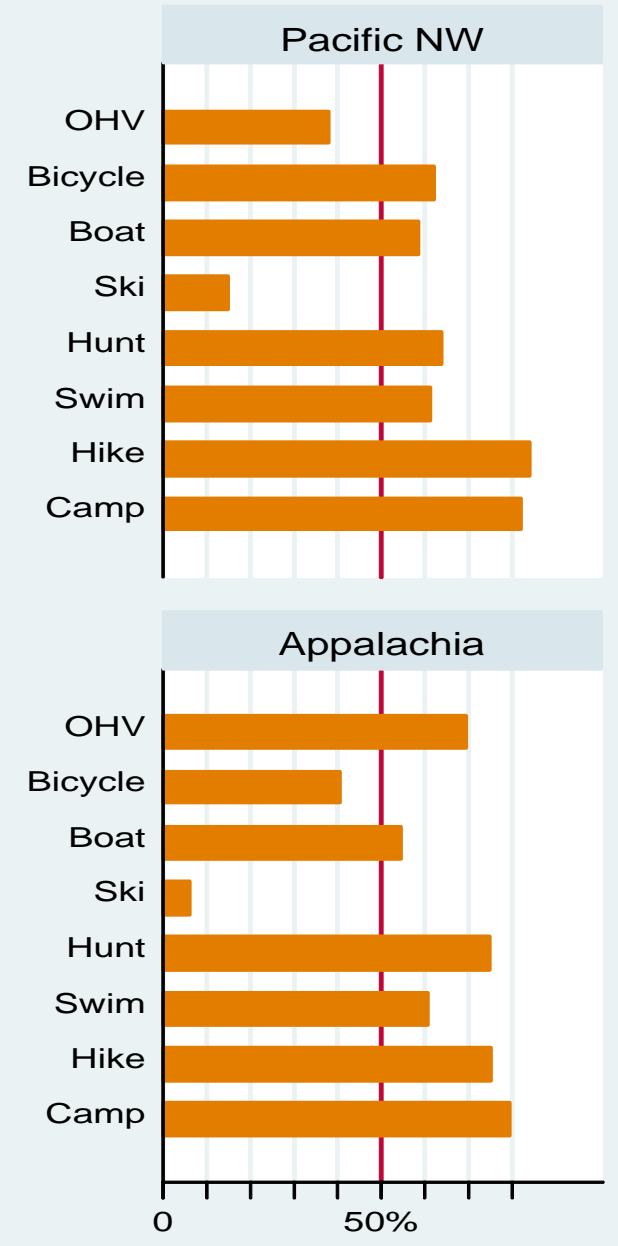
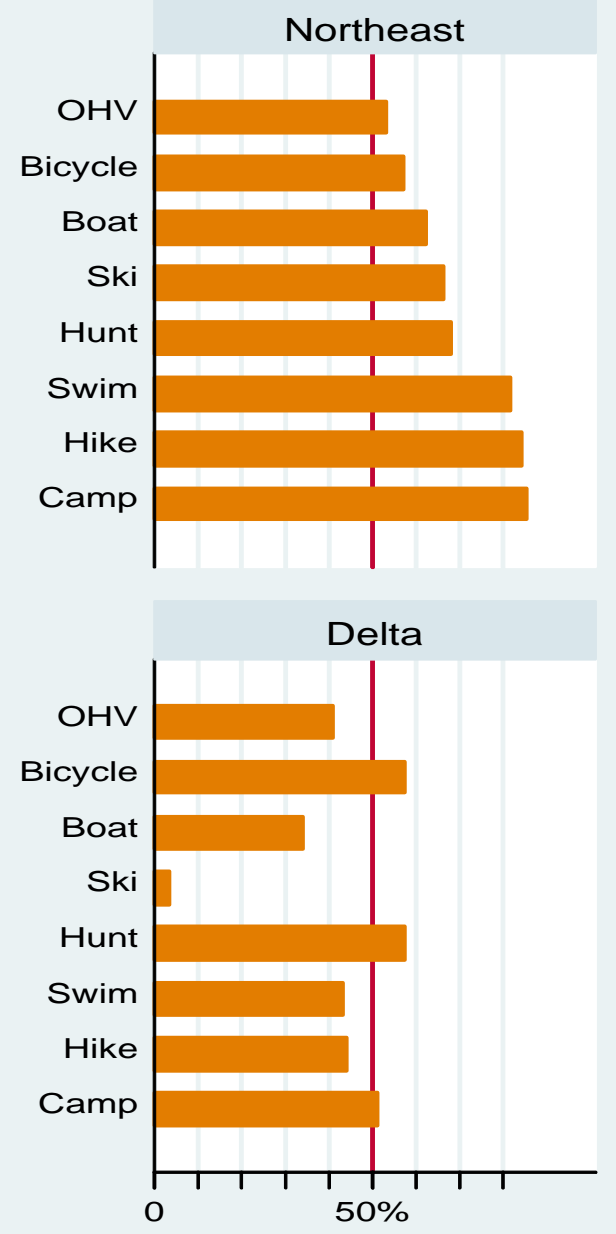

Do you or family participate in outdoor recreation? 


\section{Rural America is diverse, but there are patterns}

- Everyone values the good community spirit of trust and cooperation, and many participate in local organizations.

- Many value the natural beauty and ability to do things out doors.

- Family is important.

- But jobs are a worry, and young people are advised to leave, even as those we talked with planned to stay... 
What policy strategies will provide opportunity and shore up the middle class in rural America?

- Amenity rich places: policies for environmental protection to maintain amenities, and policies for living wages and affordable housing to assure inclusion, avoid gated communities

- Declining places: build on historical human and social capital - New Homestead Act-like policies

- Poor places with low education, high dependency, limited future prospects: Invest in human capital: early childhood education, charter schools, technical colleges; restore natural environment 
Havens Center, University of Wisconsin March 12, 2008

\section{Carsey Institute \\ University of New Hampshire \\ Durham, NH 03824}

\section{Building Knowledge for Families and Communities}

http://www.carseyinstitute.unh.edu 